\title{
SANT ESTEVE DE BANYOLES: DEL PATROCINIO REGIO AL PONTIFICIO (IX-XI)*
}

por

\author{
JOSÉ IGNACIO VIDAL LIY \\ Instituto de Historia, CSIC
}

RESUMEN: En este artículo se estudia el desarrollo de las relaciones políticas que durante la Alta Edad Media el monasterio de Sant Esteve de Banyoles contrajo con diferentes poderes políticos: la monarquía carolingia, el papado y en última instancia con los condes de Besalú. Se ba evitado cualquier enfoque localista o regionalista y, por el contrario, se ha tratado de llevarlo a cabo teniendo en cuenta la importancia que para la futura evolución de las relaciones institucionales de los establecimientos religiosos en los siglos posteriores tuvo la tradición carolingia.

Palabras clave: Monasterios. Sant Esteve de Banyoles. Privilegio de Inmunidad. Monarquía carolingia. Papado. Condado de Besalú. Condado de Barcelona. Relaciones de dependencia.

ABSTRACT: This paper deals with the development of the political relationships of the abbey of Sant Esteve de Banyoles with the Carolingian kings, the papacy and the counts of Besalu in the Early Middle Ages. Trying to avoid a localist or regionalist point of view, it also stresses the importance of the Carolingian tradition in the subsequent evolution of the institutional relationships of ecclesiastical domains.

* La realización de este trabajo nunca hubiera sido posible sin la estimable colaboración de María Isabel Loring García, cuya ayuda, condescendencia y constancia han sido determinantes. No sólo he de agradecerla esta labor sino también quisiera mostrar mi aprecio por las dosis de paciencia que ha invertido en las discusiones planteadas. Por esta y otras muchas razones, queda exhimida de cualquier error que se contemple en este artículo achacables todos éstos a mi exclusiva responsabilidad.

1 ABADAL I ViNYALS, Ramon d': «La vida monàstica després de l'expulsió dels sarraïns» en Dels visigots als catalans, I, Edicions 62, Barcelona, $1986^{3}$, p. 373; SALRACH I MARÉs, Josep María: El procés de formació nacional (segles VIII-IX), I, El domini carolingi, Edicions 62, Barcelona, 1978, pp. 54-56. 
KEY WORDS: Sant Esteve de Banyoles. Immunities. Carolingian Kings. Papacy. Counts of Besalú. Counts of Barcelona.

El monasterio de Sant Esteve de Banyoles fue levantado hacia los años 812815 por el vir religiosus Bonitus en un lugar yermo y deshabitado de la localidad del mismo nombre (pagus de Besalú), en el mismo emplazamiento donde antiguamente existió una iglesia- «ubi antiquitus ecclesia fundata fuerat»-. Según algunos estudiosos, su fundación se corresponde con la "primera generación» de fundaciones monásticas llevada a cabo durante los reinados de Carlomagno y de su sucesor Luis el Piadoso ${ }^{2}$. La temprana vinculación vasallática de este monasterio con la monarquía carolingia, creada a partir del año 822 tras la encomendación del abad Mercoral con este último emperador, y su larga perduración hasta al menos la mitad del siglo $\mathrm{x}$, ha sido uno de los motivos que nos ha llevado a escoger a este monasterio como modelo para estudiar el proceso de instauración de la autoridad pontificia sobre el mismo a partir de una situación inicial de dependencia con el monarca franco. La importancia de Sant Esteve de Banyoles en la Alta Edad Media fue considerable puesto que dispuso de cinco privilegios de inmunidad y de dos bulas pontificias, documentos que ratifican en cierta manera que el prestigio social, político y religioso del mismo fueron mayores de lo que habitualmente se le ha venido concediendo en los estudios de la Catalunya altomedieval.

No obstante, la documentación de este monasterio para los siglos IX-XI se ha conservado de forma muy fragmentaria, y constituye un problema considerable en la obtención de un adecuado conocimiento del centro para este periodo. Permite, eso sí, atender con cierta holgura el análisis de la dependencia de Sant Esteve de Banyoles con los diferentes poderes políticos, la monarquía carolingia en primer lugar y el papado posteriormente. Con objeto de poder seguir con claridad este proceso, se ha estructurado el trabajo en tres apartados. En el primero de ellos, que abarca el siglo IX y primera mitad del X, se abordará de forma muy somera los orígenes de la vinculación vasallática del monasterio con la dinastía carolingia, y cuyo repaso consideramos imprescindible para una adecuada comprensión del desarrollo de las relaciones entre el poder condal y el episcopal sobre los establecimientos abaciales en la décima centuria. Se hará en este apartado especial hincapié en la pervivencia del patrocinio regio, concretada fundamentalmente en las sucesivas renovaciones del privilegio de inmunidad - la mayoría de ellas en el siglo IX-, aunque algunas otras intervenciones de Carlos el Simple y de Luis de Ultramar sobre el monasterio revelan una importante actividad regia a lo largo de la primera mitad del siglo X. Consideramos que es importante tener siempre presente la implantación caro-

2 ABADAL I VINYALS, Ramon d': «La vida monàstica després de l'expulsió dels sarraïns» en Dels visigots als catalans, I, Edicions 62 , Barcelona, $1986^{3}$, p. 373; SALRACH I MARÉs, Josep María: El procés de formació nacional (segles VIII-IX), I, El domini carolingi, Edicions 62, Barcelona, 1978, pp. 54-56.

Hispania, LXI/2, núm. 208 (2001) 417-448 
lingia en los condados catalanes puesto que el patrocinio regio marcó en definitiva las líneas de actuación, las pautas o el modelo tanto para las futuras actuaciones de los condes sobre las casas monásticas como para el establecimiento del patrocinio pontificio sobre las mismas en el siglo XI. El segundo apartado se corresponde con la segunda mitad del siglo X y comienzos del XI (1017), y en él se atiende a las repercusiones que sobre las instituciones eclesiásticas tuvo el ascenso de los poderes locales del reino franco y que abrirán un marco de relaciones de condes y centros religiosos con Romä. Para el asunto que aquí nos ocupa supondrá la vinculación de Sant Esteve de Banyoles con el pontificado. Para ello será necesario desentrañar el análisis de aquellas estrategias utilizadas por los condes para atribuirse máximas competencias de soberanía entre las cuales, como es lógico, se encontraban las de índole religiosa. Finalmente, en un tercer apartado, que abarca el resto del siglo XI, se contempla el proceso de consolidación de la autoridad pontificia sobre el monasterio de Sant Esteve de Banyoles, y que en buena medida fue resultado de la consolidación del acercamiento de los condes al papado.

\section{El PATROCiNIO CAROLINGIO (822-948)}

\subsection{El privilegio de inmunidad. Causas}

El patrocinio regio sobre los centros monásticos, uno de los principales ejes de la política carolingia, perseguía la estabilización del equilibrio entre las aristocracias laicas y religiosas del Imperio. El control monárquico sobre las instituciones eclesiásticas sin embargo terminó siendo a finales del siglo $\mathrm{X}$ el modelo de la política condal durante el proceso de formación y maduración de los llamados «Principados Territoriales», que elevó a los condes a una categoría superior, similar a la de los monarcas en el ejercicio de competencias religiosas dentro del reducido ámbito de sus propios condados. Dada esta situación, es lógico que el punto de partida que se ha escogido en este trabajo sea el estudio de la relación de dependencia que Esteve de Banyoles contrajo con los reyes carolingios a partir de la concesión del privilegio de inmunidad, el cual, al someter de forma directa al monasterio con éstos, prohibía cualquier injerencia o intervención del poder condal o de sus agentes en el ámbito monástico, definiendo de esta forma las bases de la relación de los monjes con condes, obispos y monarcas. Las consecuencias se traducían en el traspaso de aquellas competencias y prerrogativas que anteriormente desempeñaba el conde en el dominio de la abadía para ser en adelante el abad el único responsable ante el rey de la gestión de aquellas, si bien podía delegar estas funciones en un representante (advocatus).

Como ya se adelantó anteriormente, Sant Esteve de Banyoles recibió dicho privilegio del rey Luis el Piadoso en 822 cuando el abad Mercoral, acompañado por Rampón, conde de Barcelona y Girona, se presentó en la ciudad de Attig-

Hispania, LXI/2, núm. 208 (2001) 417-448 
ny al emperador Luis el Piadoso con la intención de encomendarse a su protección - "quem in nostra praesentia adducens in manibus nostris eum commendavit»3-. Según el propio privilegio de inmunidad resultante de esta acción indica, la dicha encomendación del abad se llevó a cabo mediante la fórmula de la inmixtio manuum, acto que continuó con la repetida concesión del mencionado privilegio: «Sed liceat memorato abbati suisque successoribus res praedicti monasterii sub immunitatis nostrae defensione quieto ordine possidere» ${ }^{4}$.

La concesión de dicho privilegio a este monasterio pensamos que se encuadra dentro de la práctica generalizada para todo el conjunto del Imperio destinada a neutralizar el poder magnaticio a través de un equilibrio entre la aristocracia laica y la religiosa. Pero además, también influyeron otros factores más concretos. Uno de ellos fue la propia necesidad de la monarquía carolingia de fortalecer su autoridad en los territorios recientemente incorporados al sur de los Pirineos. El segundo responde a los planes de homogeneización religiosa para los distintos cenobios del Imperio. Los privilegios de inmunidad contribuyeron en buena medida a ello al regular la implantación de la regla benedicti$\mathrm{na}^{5}$ en los monasterios inmunes, cumpliendo así con el mandato real decretado por Luis el Piadoso en el sínodo de Aquisgrán de 817. Este hecho cobra especial importancia en los condados catalanes, en donde pervivían tradiciones religiosas hispanovisigodas que diferían de las de la iglesia franca y que dieron lugar a una de las querellas teológicas más significativas de la iglesia carolingia, la querella adopcionista, doctrina que fue condenada en sucesivos concilios celebrados en el reinado de Carlomagno (Ratisbona, 792; Frankfurt, 794; Roma, 798; Aquisgrán, 799) ${ }^{6}$.

3 ABADAl I VINYALS, Ramon d': Catalunya Carolingia. Els diplomes carolingis a Catalunya, II, Editorial Patxot, Barcelona, 1950, (Banyoles) doc. I, p. 45. (En adelante esta obra se abreviará como CC).

4 «Quapropter praecipientes jubemus ut memoratus Mercoralis abbas cum monachis sibi ad regendum commissis, sive cum rebus ad dictum monasterium legaliter aspicientibus, sub nostro constituere mundoburdo et immunitatis defensione, ut nullus quilibet ex judiciaria potestate in ecclesias aut loca vel agros seu reliquas possessiones memorati monasterii, quas moderno tempore infra ditionem imperii nostri juste et legaliter possidet et quae deinceps in jure ipsius sancti loci voluerit divina pietas augere, ad causas audiendas vel freda exigenda aut mansiones vel paratas faciendas aut fidejussores tollendos aut bomines ipsius monasterii distrigendos nec ullas redibitiones aut illicitas occasiones requirendas, nostris et futuris temporibus ingredi audeat vel ea quae supra memorata sunt penitus exigere praesumat. Sed liceat memorato abbati suisque successoribus res praedicti monasterii sub immunitatis nostrae defensione quieto ordine possidere». CC, II, p. 46.

5 Así en el privilegio de inmunidad del año 822 para Sant Esteve de Banyoles se dice que "quamdiu inter se tales invenire potuerint qui ipsam congregationem secundum regulam sancti Benedicti regere valeant». v. supra nota 3.

6 Sobre la cuestión adopcionista, v. ABADAl I VINYALS, Ramon d': La batalla del Adopcionismo en la desintegración de la Iglesia visigoda, Barcelona, 1949; RuU RiU, Manuel: «Revisión del problema adopcionista en la diócesis de Urgel», Anuario de Estudios Medievales, 1 (1964) 77-96; BARBERO DE AGUiLerA, Abilio: «Los «Síntomas españoles» y la política religiosa de Carlomagno», en La sociedad visigoda y su entorno bistórico, Siglo XXI, Madrid, 1992, pp. 122-131.

Hispania, LXI/2, núm. 208 (2001) 417-448 


\subsection{El patrocinio regio y su pervivencia. (822-948)}

Las renovaciones de los privilegios de inmunidad son uno de los elementos clave para valorar la impronta o la presencia de la dinastía carolingia en los condados catalanes, pues son testigo escrito de la consideración de señores de que gozaban los monarcas francos cuando menos para las instituciones o personas beneficiadas. $Y$ así parecen evidenciarlo las cuatro renovaciones del privilegio de inmunidad llevadas a cabo por los sucesores de Luis el Piadoso hasta el año 916 para Sant Esteve de Banyoles que dejan bien manifiesto la vitalidad de la monarquía franca como patronos de esta casa monástica. Pero además según se desprende en otras intervenciones regias posteriores, se puede alargar más la autoridad regia y extenderla hasta al menos el final de la primera mitad del siglo $\mathrm{X}$. Así las vinculaciones a la iglesia de Narbona ordenadas por Carlos el Simple (899 y 918-919) o la segregación de Sant Pere de Rodes de su dependencia de Sant Esteve de Banyoles (944-948) confirmada por Luis de Ultramar así lo testimonian. Pero empezaremos primero por estudiar las mismas renovaciones.

Como ya se ha indicado, las renovaciones del privilegio de inmunidad son un reflejo de la importancia que sobre todo las instituciones religiosas, principales beneficiadas, confirieron a sus respectivas relaciones de dependencia con la dinastía reinante, al haberla reconocido como garantía en la defensa y ampliación de sus derechos y propiedades, es decir, de las fuentes y bases de su poder social y económico. Pero también el privilegio de inmunidad responde al interés de la propia monarquía por afianzar o reforzar su autoridad en unos territorios determinados. En el caso de Sant Esteve de Banyoles éste último factor es quizá el que mejor aclara las renovaciones del privilegio, puesto que por lo general éstas tienen lugar en contextos de restauración del poder monárquico tras sofocar revueltas o movimientos levantiscos de la aristocracia al sur del reino.

Se han conservado tres renovaciones del privilegio de inmunidad para el monasterio de Sant Esteve de Banyoles - una de Carlos el Calvo (866) ${ }^{7}$, otra de Luis el Tartamudo (878) ${ }^{8}$ y y una última de Carlos el Simple (916) bién se tienen noticias de otras dos renovaciones concedidas por Carlos el Calvo, una en la ciudad de Tolosa y cuyo contenido ha sido reconstruido por Ramon d'Abadal (844), y otra sucedida durante la dieta de Attigny (870) pero cuyo documento en sí lamentablemente se ha perdido ${ }^{10}$.

La primera de estas renovaciones se llevó a cabo en 844 una vez que Carlos el Calvo procede a restaurar su autoridad en el sur del reino tras derrotar en

7 CC, II, pp. 55-57.

8 CC, II, pp. 58-61.

9 CC, II, pp. 62-64.

10 ABADAL I VINYALS, Ramon d': Els primers comtes catalans, Vicens Vives, Barcelona, 1961, pp. 117. El documento que contiene las referencias a este privilegio se conserva en MONSALVATGE I Fossàs, Francisco: Noticias Históricas del condado de Besalú (en adelante NH), XI, pp. 133-137 y en CONSTANS I SERRATS, Ll.: Diplomatari de Banyoles (en adelante DB), I, doc. 13, pp. 179-182. 
Tolosa al poderoso rebelde Bernardo de Septimania, que además de conde de Tolosa (835-844), lo era también de Narbona y Barcelona (826-844), y partidario de la candidatura al trono de Pipino ii de Aquitania frente a la de Carlos el Calvo ${ }^{11}$. Tras tomar éste la ciudad, las jerarquías eclesiásticas, obispos y abades del ámbito catalán y septimano, acuden a la sede del rey, provisionalmente instalada en la iglesia de Saint Sernín, para confirmar y jurar su fidelidad al monarca, procediéndose así a un claro reconocimiento de la autoridad regia en el sur del reino. Es en este contexto cuando tuvo lugar la primera renovación del privilegio de inmunidad, siendo Petrus el abad del monasterio ${ }^{12}$.

Recién entrada la década de los años sesenta, nuevos desórdenes hacen peligrar la autoridad de Carlos el Calvo al sur del reino. En esta ocasión se trata de la actitud levantisca de Humfrido, quien desde el año 858 gobernaba el marquesado de la Gotia, es decir, Narbona y sus satélites más los condados de Barcelona, Girona, Empúries y Rosellón. Desde 862 protagonizó una ambiciosa política que le llevó a hacerse por la fuerza con los condados de Tolosa, cuyo conde Ramón fue asesinado, y los de Carcasona-Rasés. Tras dos años de resistencias, en 865 el insurrecto huye a Italia, en donde tenía sus bienes patrimoniales, recuperando Carlos el Calvo el control de estos territorios, que procedió a repartir de nuevo entre otros próceres del reino recayendo la mayor parte de la Marca, - - el condado de Narbona, sus satélites septimanos y los condados de Barcelona y Rosellón - en la persona de Bernardo de Gotia; el de Tolosa fue concedido a otro Bernardo, el hijo del asesinado conde Ramón; el de Carcasona-Rasés fue conferido a Oliba, el de Girona a Otger y el de Empúries a Sunyer. No obstante, el apoyo de los nuevos condes, a quienes se recompensará en algunos casos con importantes concesiones territoriales como demuestra el diploma concedido a Oliba en $870^{13}$, no debía resultar suficiente, sino que para la monarquía era también importante y necesario el respaldo de los círculos eclesiásticos, cuya fidelidad se había mantenido más firme que el de los anteriores y aún más fiable. Como se ve, fue de nuevo una nueva revuelta, en esta ocasión la del marqués Humfrido, el motivo que ocasionó la segunda renovación del

11 La de este rey estuvo defendida por Sunifredo, conde de Urgell-Cerdaña y por Sunyer, de Empúries-Rosellón ABADAL I VINYALS, Ramon d’: «El domini carolingi a la Marca Hispànica» en Dels visigots als catalans, I, Edicions 62, Barcelona, 19863, pp. 142-144.

12 «idem monasterium cum monachis et cunctis sibi pertinentibus rebus [...] sub immunitatis nostrae tuitione reciperemus» $C C$, II, pp. 49-54; las noticias referidas al abad y a su pertición sobre la renovación de la inmunidad se encuentran recogidas en el privilegio de inmunidad del año 866: "quia venerabilis Petrus, abbas monasterii quod dicitur Balneolas quod est situm in pago Bisuldunensi, constructum scilicet in bonore sancti Stephani protomartyris Christi, adiens serenitate nostrae fastigia, obtulit auctoritatis nostrae preceptum dudum a nobis antecessori ejus Heliae venerabili abbati factum, in quo continebatur qualiter idem monasterium cum monachis inibi Deo famulantibus omnibusque ei pertinentibus sub immunitatis nostrae munimine pleniter susciperemus», CC, II, p. 55.

13 ABADAl I Vinyals, Ramon d': Els primers comtes catalans, Vicens Vives, Barcelona, 1961, p. 8. El documento citado en Tessier, G.: Recueil des Actes de Charles Il le Chauve, roi de France, II, Paris, Académie des Inscriptions et Belles-Lettres, 1952, núm. 341.

Hispania, LXI/2, núm. 208 (2001) 417-448 
privilegio de inmunidad del monasterio de Sant Esteve de Banyoles, otorgada en la ciudad de Quierzy en 866, regido en este año por el abad Elías e idéntica en su contenido a la anterior, a la del año $844^{14}$.

Se ha conservado alguna noticia de un tercer privilegio del mismo monarca otorgado con ocasión del viaje que en 870 realizó Ansemundo, abad de Sant Esteve de Banyoles a la ciudad de Attigny para solucionar a su favor las disputas que venía manteniendo con San Policarpio de Rasés acerca de unas cellae situadas en el condado de Peralada, concretamente Sant Pere de Rodes, Sant Joan ses Closes y Sant Cebrià de Pineda ${ }^{15}$. Privilegio que fue aportado por Ansemundo cuando de nuevo en 880 se trató el tema de las disputadas posesiones con el monasterio contrincante en un pleito celebrado en la localidad ampurdanesa de Castelló d'Empúries en presencia de Delà, conde de Empúries y Girona, y de Teutari, diocesano de Girona ${ }^{16}$. Esta tercera renovación muestra que éstas, además de realizarse tras la neutralización de rebeliones aristocráticas en las que peligraba la protección y los privilegios del monasterio, también se llevaban a cabo en todas aquellas situaciones en las que fuese precisa la protección regia. Ello viene a demostrar que la dependencia del monasterio con el rey carolingio no era una relación puramente nominal, o lo que es lo mismo, que la autoridad regia permanecía fuerte en los condados catalanes. Y así era hasta el punto que determinó el viaje del abad Ansemundo a la corte regia para disponer de un nuevo documento regio que protegiera sus intereses y a los de su comunidad frente a las injerencias de otros poderes religiosos, en este caso, el monasterio de San Policarpio de Rasés. Es esta una noticia, que aunque conocida indirectamente, ejemplifica de forma significativa la reciprocidad de intereses de la relación de dependencia que venían manteniendo desde 822 abades y monarcas. Por una parte, el abad buscaba del monarca su señor, la protección de sus pertenencias; por su parte, al rey se le presentaba una inmejorable ocasión para afianzar su poder en los condados meridionales en un contexto tan difícil y crítico como la dieta de Attigny ${ }^{17}$.

En esta asamblea Carlos el Calvo no pudo alcanzar el equilibrio deseado con la nobleza. De hecho el debilitamiento de la monarquía carolingia se acele-

14 CC, II, pp. 49-54.

.15 ABADAL I VINYALS, Ramon d': Els primers comtes catalans, Vicens Vives, Barcelona, 1961, pp. 64. El documento que contiene las referencias a este privilegio se conserva en MONSALVATJE I Fossàs, Francisco: Noticias Históricas del condado de Besalú (en adelante NH), XI, pp. 133-137 y en CONSTANS I Serrats, Lluis: Diplomatari de Banyoles (en adelante DB), I, doc. 13, pp. 179-182.

$16 \mathrm{NH}, \mathrm{XI}$, pp. 133-137; DB, I, doc. 13, pp. 179-182.

17 A pesar de que el monasterio de Sant Esteve de Banyoles fue el que salió beneficiado del pleito, lo cierto es que los derechos del monasterio carcasonés no debían de ser menores, a pesar tan sólo de disponer de un documento regio que avalara sus derechos. Aunque no se puede demostrar creemos que los derechos de este monasterio de San Policarpio deben remontarse a tiempos cercanos a su fundación (782), cuando su fundador Atalà fracasa en la fundación de una abadía en el condado de Peralada (780). ABADAL I VINYALS, Ramon d': «La vida monàstica després de l'expulsió dels sarrains» en Dels visigots als catalans, I, p. 372. 
ró en los últimos años del gobierno de éste, como demuestra la capitular de Quierzy-sur-Oise (877), en la que se aceptaba la hereditariedad de los cargos y de los beneficios para todos aquellos que acompañaran al rey en la campaña de Italia, si bien es cierto también el rey se reservaba el derecho a revocar aquellos nombramientos que no le parecieran oportunos. A pesar de esta cláusula destinada a preservar la autoridad del monarca sobre los magnates, en adelante los reyes tendrían dificultades para aplicarla, o lo que es lo mismo, para detener el progresivo auge magnaticio. Esta debilidad monárquica frente a la nobleza del reino quedó manifiesta con la actitud beligerante de Bernardo de Gotia, marqués y conde de Narbona, Barcelona y Rosellón (865-878), y de Bourges y Autun (876-878). Sus ambiciones políticas le llevaron a declararse en rebeldía en contra del monarca aprovechando su ausencia durante la campaña italiana. Luis ii el Tartamudo, sucesor en el trono, puso fin a esta sedición con ocasión del solemne concilio celebrado en la localidad de Troyes en 878 , a raíz de la presencia del papa en el reino.

A esta reunión acudieron las autoridades eclesiásticas más influyentes del reino. De las tierras catalanas, hay constancia de la asistencia de los obispos de Barcelona y Girona, además de los abades de Santa María d'Arles y de Sant Esteve de Banyoles, Castellà y Ansemundo respectivamente ${ }^{18}$. Todos ellos recibieron del rey una generosa confirmación del privilegio de inmunidad, y así, el monasterio de Sant Esteve de Banyoles recibió además de la renovación del antiguo privilegio que aseguraba las cellae del condado de Peralada disputadas en estos años por el monasterio de San Policarpio de Rasés, la concesión del mansionaticum y del pascuaticum.

Tras la celebración del concilio de Troyes (878), el monarca Luis el Tartamudo tomó una serie de disposiciones respecto a los honores detentados por Bernardo de Gotia, que fueron atribuidos a Teodorico, camarero real, Bernardo, conde de Auvernia y otros que los Anales de Saint Bertin no citan nominalmente. Según Abadal habría que identificar con Wifredo el Velloso, conde de Cerdaña, al que ahora se atribuiría además Barcelona y Girona, y Miró, conde del Conflent, ahora investido con el de Rosellón ${ }^{19}$. Esta sería la última intervención directa de los monarcas carolingios en la designación de los titulares de los honores condales al sur del reino, hecho que encuentra su explicación tanto en el triunfo de la hereditariedad de los cargos condales como en el declive de la monarquía carolingia. Ésta repercutió en la propia expedición de diplomas regios, ya que como ha puesto de relieve Zimmermann a partir de este año se detecta una fuerte disminución del número de estos documentos ${ }^{20}$. En el caso de Sant Esteve de Banyoles tan sólo disponemos de una última renovación

18 ABADAL I VINYALS, Ramon d': Els primers comtes catalans, pp. 62 y ss.

19 ABADAL I VINYALS, Ramon d': Els primers comtes catalans, pp. 62 y ss.

20 ZimmermanN, M.: «Naissance de un principauté: Barcelone et les autres comtés catalans aux alentors de l'an mil», en Cataluña i França meridional a l'entorn de l'any mil, Generalitat de Cataluña, Departament de Cultura, Barcelona, p. 112.

Hispania, LXI/2, núm. 208 (2001) 417-448 
del privilegio de inmunidad que fue concedida por Carlos el Simple en la ciudad de Heristal en 916. Ramon d'Abadal cuestionó la fiabilidad de este documento al entender que se trata de una copia exacta del último privilegio concedido al monasterio en 878 al no reflejar las transformaciones referidas a la discutidas cellae del condado de Peralada, las cuales en 899 fueron traspasadas a la sede episcopal de Girona, durante la "ola de legitimismo" que sucedió a su reposición en el trono ${ }^{21}$. Sea a no producto de la dejadez de la cancillería regia, sin embargo la misma expedición del documento refleja en sí la pervivencia de la dependencia y la fidelidad de Sant Esteve de Banyoles con la dinastía carolingia. $\mathrm{Y}$ es este factor el que nos interesa resaltar frente al primero: la vigencia que en el paso del siglo IX al X disfrutaba aún en los condados catalanes la dinastía reinante a pesar de las dificultades que ésta sufría a estas alturas de siglo.

Hasta el momento se han entendido a los privilegios de inmunidad de Sant Esteve de Banyoles como la materialización jurídica de la relación de dependencia personal de este monasterio con la monarquía, la cual era fruto a su vez de la reciprocidad de intereses por ambas partes. Sus mismas renovaciones también demuestran el interés de abades y reyes por mantener vigente esta relación, ya que respaldaba el poder local de los primeros y afianzaba la autoridad de los segundos. Es razonable entonces que todas estas renovaciones se expidan siempre en momentos de restauración del poder monárquico, tras acabar con las rebeliones de Bernardo de Septimania (844), del marqués Humfrido (866), de Bernardo de Gotia (878) o con ocasión del programa restaurador de Carlos el Simple (916), tras su reposición a la muerte del robertino Eudes (892). En este sentido creemos conveniente redundar en el hecho de que el privilegio de inmunidad fue un importante instrumento en manos de la monarquía carolingia para conservar su autoridad al sur del reino.

Como se ha visto, la última renovación del privilegio de inmunidad data de comienzos del siglo x (916). No obstante, disponemos de otras evidencias que prueban que la actuación del monarca como patrono del monasterio se prolongó hasta al menos los años centrales de esta centuria. Una de estas intervenciones es la confirmación de la dependencia de Sant Esteve de Banyoles a la iglesia de Narbona, testimoniada en dos privilegios de Carlos el Simple concedidos a esta iglesia (899 y 918-91922). Hasta el momento, de esta vinculación sólo se conocen lamentablemente un par de regesta, por lo que no nos es posible conocer plenamente el alcance de esta relación, si bien al menos dejan constancia de la activa intervención de la monarquía carolingia al sur del reino estimulada sin duda por la necesidad cada vez más urgente de disponer de vasallos que les afirmaran en un poder cada vez más tambaleante. Dos privilegios regios de Luis IV de Ultramar a favor del monasterio de Sant Pere de Rodes (944 y 948)

21 ABADAL I VinYals, Ramon d': Els primers comtes catalans, Vicens Vives, Barcelona, 1961, pp. 263-264.

${ }^{22} \mathrm{DB}, \mathrm{I}$; docs. 16 y 19.

Hispania, LXI/2, núm. 208 (2001) 417-448 
muestran cómo las intervenciones monárquicas se continuaron en el ámbito de Sant Esteve de Banyoles unos años más tarde. En el primero de ellos $(944)^{23}$, el rey sitúa al monasterio de Sant Pere de Rodes bajo su protección y le concede el privilegio de inmunidad y en consecuencia le sustrae de sus dependencia con la casa de Banyoles. En el segundo $(948)^{24}$, cita a su presencia en la ciudad franca de Laon a Tassi - artífice de la nueva vinculación de Sant Pere de Rodes con Luis IV-, y al abad de Banyoles, y éste último reconoce la independencia de la abadía ampurdanesa a cambio de una compensación monetaria (ratione). A pesar de que este proceso resulta interesante por la implicación del monasterio objeto de nuestro estudio, no obstante preferimos aplazar su análisis al siguiente apartado en el que se estudiará con mayor detenimiento la permanencia de la tradición carolingia a finales del siglo $\mathrm{x}$ en los condados catalanes.

Esta es la última intervención de monarcas carolingios de la que tenemos constancia para el monasterio de Sant Esteve de Banyoles. Pero, no porque no hayan quedado más testimonios documentales se ha de sospechar que ésta acabara en estos años. Aunque los testimonios escritos de la presencia carolingia al sur de los Pirineos a finales del siglo décimo es escasa, revelan no obstante que siguió presente. Así en 952 el conde Wifredo de Besalú obtuvo un privilegio de inmunidad para el recién fundado monasterio de San Pedro de Camprodón y todavía en 986, un año antes del fin de la dinastía carolingia en el trono franco, el obispo de Barcelona acudió a la sede regia en busca de un nuevo privilegio de inmunidad para su sede episcopal. No existen pruebas para mostrar la supuesta fidelidad de Sant Esteve de Banyoles hacia la dinastía carolingia hasta el año 987 pero tampoco las hay para refutarlas. En cualquier caso, la permanencia de la autoridad carolingia a finales del siglo X se abordará de inmediato, en el próximo apartado, dedicado al análisis de las nuevas formas de relación del monasterio con unos poderes locales en pleno ascenso y que terminará por desencadenar el fenómeno de los llamados «Principados Territoriales» ahora todavía en estado embrionario.

\footnotetext{
23 Como vemos, no es esta la primera ocasión en que el monarca franco actúa de forma explícita en el dominio de Sant Esteve de Banyoles. Ya con anterioridad tuvimos ocasión de comprobar que en el año 870 el abad Ansemundo del monasterio de Sant Esteve de Banyoles recurrió al rey Carlos el Calvo para que éste sancionara a su favor la posesión de las cellae que Sant Esteve de Banyoles tenía en el condado de Peralada y que si recordamos eran Sant Pere de Rodes, Sant Cebrià de Pineda y Sant Joan ses Closes. Pues bien, sesenta años más tarde Luis de Ultramar, se hace eco de las protestas de Tassi, principal protagonista en estos años del impulso del monasterio, y accede cumplir con los deseos del demandante, y acoge al monasterio bajo su patrocinio y lo independiza de Sant Esteve de Banyoles (944). CC, II, pp. 226-228.

24 CC, II, doc. II, pp. 229-229-231.
} 


\section{HACIA EL PATRONATO PONTIFICIO}

\subsection{La crisis dinástica. Decadencia y autoridad}

A lo largo de todo el siglo $\mathrm{X}$, los monarcas carolingios continuaron concediendo y renovando privilegios de inmunidad a las instituciones eclesiásticas de las diócesis catalanas con el fin de mantener su autoridad en los territorios meridionales del reino. Es cierto que desde el primer tercio de la centuria la dinastía reinante se hallaba ya inmersa en un claro proceso de decadencia, pero pese a ello, sus monarcas todavía estaban capacitados para intervenir directamente en establecimientos religiosos, creando o incluso reforzando de esta forma los lazos feudovasalláticos contraídos por éstos desde antiguo. Así, los monasterios de Sant Pere de Rodes (944), Sant Pere de Camprodón (952) y los de Sant Pol de Mar y Sant Feliù de Guíxols (968), unidos de forma coyuntural bajo el mandato de su abad Sunyer, reciben por vez primera el privilegio de inmunidad ${ }^{25}$, mientras que a los de Santa María de Ripoll (938), Sant Cugat del Vallès (938, 986), Sant Pere de Rodes (948), Sant Miquel de Cuixà (952), se les confirman privilegios anteriores ${ }^{26}$. Las confirmaciones regias de patrimonios monásticos, tan o más abundantes incluso que los documentos anteriores, también fueron otra de las formas bajo la que los monarcas carolingios manifestaron su condición de patronos de abadías. Es el caso de Sant Pere de Rodes (953, 982), Sant Miquel de Cuixà (958), Sant Genís Les Fonts (981), Santa María de Ripoll (982), o la iglesia-catedral de Vic (938) si bien en este último caso Luis iv de Ultramar se limita sólo a confirmar la donación del tercio de la moneda cedida años antes por el conde Guifré-Borrell de Barcelona (911) ${ }^{27}$.

Todas estas renovaciones ya fueran de privilegios, ya de bienes territoriales, reflejan la condición de patronos de los monarcas carolingios de las diferentes casas monásticas. Hasta tal punto estaba extendida la conciencia de vasallaje, que en fechas tan tardías como el año 986 el abad Odó de Sant Cugat del Vallès acude a la corte regia para solicitar del rey Lotario la restauración de los documentos que fueron quemados por la incursión de Almanzor del año anterior. Aprovechando esta situación el propio monarca se reconoce como la única autoridad con competencias para restaurar los bienes y los documentos del monasterio: «Si loca paganorum tirannide destructa prediorum sanctis aliquando traditorum restaurando nostre benvolentie muniminis firmitatem eis adbibemus, id proculdubio ad nostre remedium anime profuturum esse non dubitamus... Concedimus itaque

${ }_{25}$ CC, II, pp. 226-228 (Sant Pere de Rodes); CC, II, pp. 77-79 (Camprodón); CC, II, pp. 203204 (Sant Pol de Mar y Sant Feliù de Guìxols).

26 CC, II, pp. 162-165 (Santa María de Ripoll); CC, II, pp. 192-193 y pp. 198-200 respectivamente (Sant Cugat del Vallès); CC, II, pp. 229-231 (Sant Pere de Rodes); CC, II, pp. 92-93 (Cuixà).

27 CC, II, pp. 233-234 y pp. 241-244 (Sant Pere de Rodes); CC, II, pp. 94-99 (Sant Miquel de Cuixà); CC, II, pp. 210-213 (Sant Genís Les Fonts); CC, II, pp. 170-174 (Santa María de Ripoll); CC, II, pp. 300-301 (Vic). 
predicto cenobio omnes res quas per precepta nostrorum predecessorum, scilicet Karoli Magni seu Ledovici, genitoris nostri, vel per scripturas aliorum Christi fidelium combustas esse novimus per infestationem paganorum, sicque, ut prenotatum est, predicti abbatis peticionem recipientes, prelibato cenobio renovabile preceptum fieri jussimus de rebus omnibus ad idem cenobium pertinentibus in presenti vel in postmodum concedendis» ${ }^{28}$.

Además de ejemplos de este tipo, la documentación presenta otras intervenciones directas del monarca sobre abadías y que, como se tendrá oportunidad de comprobar, van más allá de una posible legitimación protocolaria de los documentos. Son los casos de la segregación del cenobio de Sant Pere de Rodes del dominio de Sant Esteve de Banyoles (944-948) - muy interesante para nuestro análisis dada la implicación de este último monasterio-, y el permiso del rey Lotario al abad Sunyer para legalizar de forma coyuntural la pequeña congregación monástica de Sant Feliú de Guíxols y Sant Pol de Mar (968).

El proceso de ruptura de Sant Pere de Rodes con Sant Esteve de Banyoles estuvo en buena medida motivado por las fricciones que desde al menos finales del siglo IX este último cenobio mantuvo con el de Saint Policarp de Rasés por la posesión del primero de ellos junto con otras cuantas cellae más sitas en el condado de Peralada ${ }^{29}$. La permanencia de éstas durante la primera mitad del siglo X llevó a Tassi $i^{30}$, pequeño potentado local con una fuerte influencia sobre el centro, a pedir permiso a los condes Sunifred de Barcelona-Girona y Gausfred de Empúries («suadentibus ac consentientibus Seniofredo marchione atque Goffrido comite, dirigentes») para acudir a la presencia regia y solicitar al monarca la concesión del privilegio de inmunidad y situar al monasterio bajo el patrocinio regio. Aconsejado por el obispo Gotmar, Luis IV de Ultramar atiende la petición de Tassi, acoge a Sant Pere de Rodes bajo su patrocinio y le concede por primera vez el privilegio de inmunidad y la libre elección de $a b a d^{31}$.

28 CC, II, p. 198. La conciencia de vasallaje todavía es mayor si tenemos en cuenta la opinión de Abadal quien piensa que el propio abad Odó acudió a la corte regia como enviado del conde Borrell de Barcelona para solicitar al monarca ayuda militar para detener la ofensiva musulmana.

29 Las primeros enfrentamientos documentados entre ambos monasterios ocasionaron la celebración de un pleito celebrado en la localidad de Castelló d'Empúries en el año 880 en presencia del conde Delà de Empúries. Sobre los posibles derechos del monasterio de San Policarpo de Rasés, $v$. ABADAL I VINYALS, Ramon d': Els primers comtes catalans, Vices Vives, Barcelona, 1961, p. 116. v. nota 14.

30 «Idcirco noverit omnium fidelium nostrorum tam praesentium quam et futurorum industria quoniam monachi ex coenobio beati Petri apostolorum principis, quod est situm in comitatu Petralatense, constructum vero in monte Rotas nuncupante, nostrae celsitudini quendam ex ejusdem loci prioribus, videlicet Tassium, suadentibus ac consentientibus Seniofredo marchione atque Goffrido comité, dirigentes, innoterunt nobis qualiter pro eodem monasterio longo jam tempore inter monachos coenobii beati protomartyris Stephani in Balneolas constructi et coenobitas monasterii Sancti Policarpi martiris non modica orta esset dissensio, cupientes illud utrique suae ditioni subjicere, quod per rectumm ut coram nobis protestatum est, agere non valebant». CC, II, p. 227.

31 «Unde nostro obtentu ac assensu Gotmari praesulis munificentiam nostram obnixe precati sunt quatinus jam dictum monasterium, remota totius contentionis altercatione, sub nostrae immunitatis ac defensionis tuitione ditionisque potestate manere ac consistere nostrae auctoritatis praecepto concederemus. Quorum petitionibus benigne susceptis, jussimus boc regale decretum eis fieri, per quod praecipientes jubemus ut nullus comes vel 
La comunidad monástica de Banyoles no debió quedar satisfecha con aquella determinación, pues cuatro años más tarde, en 948, Luis IV de Ultramar ha de intervenir de nuevo «ut omnes funditos inter illos divelleretur divortium et pax Christi veraque roboretur concordia». En esta nueva ocasión hay una nueva mediación de los condes Sunyer de Barcelona, de su hijo Borrell, y de los condes Gausfred de Empúries y Guifré de Besalú quienes «per commune consilium» permitieron a Acfred, abad de Sant Esteve de Banyoles, dirigirse a la corte regia junto con Tassi, para solucionar una situación con la que el primero de ellos no parecía estar demasiado acorde ${ }^{32}$. De esta forma, de acuerdo a lo que se puede interpretar del documento, parece que el rey sancionó un acuerdo previo y tácito entre Tassi y Acfred por el cual el primero daba unos bienes a la casa de Banyoles (ratione) a cambio de que el segundo aceptara la independencia del cenobio ampuritano ${ }^{33}$. Posteriormente, el monarca renueva a Sant Pere de Rodes el propio privilegio de inmunidad y la libre elección de $\operatorname{abad}^{34}$.

En este proceso se observa que la conversión de Sant Pere de Rodes en centro autónomo e inmune tuvo que contar necesariamente con la intervención

judex publicus seu quislibet ex judiciaria potestate in praedictum monasterium, ecclesias, villas, furtes vel agros, seu aliquas possessiones in quibuslibet regni nostri pagis et territoriis moderno tempore juste et legaliter memoratae ecclesiae adquisitas, seu postmodum adquirendas, ad causas audiendas vel freda exigenda, aut mansiones vel paratas faciendas, aut fidejussores tollendos vel homines ejusdem ecclesiae distringendos nec ullas redibitiones aut illicitas occasiones requirendas,... quiatinus liceat jam dictis monacbis ibidem deo famulantibus sub nostra defensione et immunitatis tuitione tranquille degere, et pro nobis ac conjuge proleque nostra seu pro statu totius ecclesiae, Dei misericordiam perpetualiter exorare». CC, II, p. 227.

32 «perspicuum esse volumus quoniam viri venerabilis vitae Acfredus, coenobii prototestis Stephani loco nuncupato Balneolas abbas, necnon et Tassius, sacrae religionis habitum simul et actum gerens, a regione Yspaniae nostram adeuntes praeminentiam, innotuere qualiter monasterium beati apostolorum principis Petri, situm in loco qui dicitur Rodas, quod antiquitus videbatur fore coenobio almi Stephani subjectum, unde non modica fuerit diu inter jam dictorum abbates et incolas coenobiorum exorta dissensio, per comune consilium illius regionis praesulum comitumve Suniarii, Gotfredi, Borrelli scilicet ac Wifredi ceterorumque nobilium utriusque ordinis virorum, immo etiam consentiente jam dicto Acfredo abbate, sub nostra scilicet scientia principalia loca consistere ditione, absque aliquo respectu blanditionis eidem coenobio exibendae praeter mutuae dilectionis obsequium». CC, II, p. 230.

33 «venerabilis vir Tassius nostrae sublimati notificare voluit quia ipse et flius ejus Hildesindus, memorati monasterii Sancti Petri jam abbas constitutus, suae proprietatis res coenobio praelibati Cbristi martyris Stephani tradere studuerit, ea videlicet ratione ut quod eis a jam dicto Acfredo abbate concessum est, a se suisque successoribus immutabiliter et inconvulse servetur». CC, II, p. 230.

34 «Quorum petitionibus libenter assensum praebentes bos nostrae mansuetudinis a pices fieri praecipimus per quos jubemus atque statuimus quod saepedictus Hildesindus abbas successoresque ejus, cum coenobio sibi commisso, sub nostrae immunitatis seu ditionis maneant tuitione, omni sedata penitus alteratione. Praecipientes ergo jubemus et perpetuo mansurum esse volumus ut nullus abbas vel quaelibet praepotens persona sed neque judex publicus in praedicto monasterio 8ullam audeat inferre inquietudinis sive indebitae requisitionis exactionem, in cellis vero seu aliis locis sibi pertinentibus atque subjectis seu agris et possessionibus, in quibuscunque consistant locis, ad causas judiciario more audiendas vel freda seu mansiones aut parafredos sive paratas exigendas, vel fidejussores tollendos aut bomines ejusdem monasterii distringendos, seu aliquas redibitiones aut exactiones aut illicitas occasiones requirendas, nullo unquam tempore ingredi audeat nec ea quae supra memorata sunt exigere praesumat». CC, II, pp. 230-231.

Hispania, LXI/2, núm. 208 (2001) 417-448 
regia. Es un caso muy significativo de la conciencia que tanto condes como abades tenían del monarca carolingio como exclusivo señor de los monasterios afectados, Sant Pere de Rodes y Sant Esteve de Banyoles. Tan o más llamativo resulta el caso de los monasterios de Sant Pol de Mar y Sant Feliú de Guixols, los cuales estuvieron unidos durante el abadiato de Sunyer (968), personaje a quien Abadal identifica con el monje homónimo que en 950 recogió la primera bula pontificia para la casa de Sant Miquel de Cuixàas

El precepto para los monasterios de Sant Feliú de Guíxols y Sant Pol de Mar fue concedido por el rey Lotario a ruegos de su madre Gerberga y de Odalrico, arzobispo de Reims ${ }^{36}$. En él se da cuenta que a presencia del rey llegó el abad Sunyer acompañado por el mencionado arzobispo rogando al monarca le concediera a sus dos monasterios el privilegio de inmunidad y acogiera a estas dos casas bajo su patrocinio ${ }^{37}$. El monarca, calificando a su acción de regalía («istam regaliter»), permite a Sunyer regir las dos casas mientras viviera («ut idem abbas Soniarius eadem duo monasteria dum ipse in carne vixerit»), si bien a su muerte ambas debían separarse y disponer cada una de abad propio fiel al monarca: "Post decessum vero ejus, separatione ab invicem facta, singulis coenobiis singuli praesint et magis prosint abbates, ad nullum principem nisi ad solum regem Franciae respicientes». Además de confirmar por separado las propiedades de cada monasterio, el monarca protege a ambos de cualquier exacción: «Insuper et boc predictis monasteriis regali licencia concedo et pro Dei amore relaxo ut nullum umquam censum vel debitum de aliqua rerum suarum possessione alicui persolvant, sed libere omnia sua nostra regali absolutione possideant et nulli umquam alterius nisi solum regali subdita sint potestati».

Otro aspecto de la continuidad con épocas anteriores se detecta en la pervivencia de los condes catalanes a la corte regia en busca de privilegios regios para las instituciones monásticas. Se han testimoniado al menos dos casos en la documentación utilizada. En la concesión del privilegio de inmunidad al monasterio de Sant Pere de Camprodón (952) se cuenta que el conde Guifré II de Besalú tras transformar la antigua iglesia allí levantada, sita en sus bienes patrimoniales (de sue bereditatis rebus), en comunidad benedictina con permiso del obispo de Girona Gotmar ${ }^{38}$ tal y como era costumbre (ut moris est), acudió a

35 ABADAL I VINYALS, Ramon d': Els primers comtes catalans, Vicens Vives, Barcelona, 1961.

36 CC, II, pp. 203-204.

37 "Quocirca notum sit omnibus presentibus scilicet et futuris fidelibus, quendam religiosum abbatem nomine Soniarium, olim a partibus Gotbici regni advenientem, serenitatis nostrae presenciam, conducente fideli nostro Odelrico Remorum metropolis archiepiscopo, adiise sibique regiae auctoritatis preceptum super duobus monasteriis a nobis fieri postulasse, quorum quidem alterum in bonore Sancti Pauli consecratum situm est in comitatu Gerundense in loco qui dicitur Maritima, alterum vero in bonore sancti Felicis in eodem comitatu in loco qui dicitur Iecsalis». CC, II, p. 203.

38 «quoniam adiens praesentiam Wifredus comes rettulit nobis qualiter quendam locellum in bonore sancti Petri, situm in pago Bisullunense, ob Dei ejusdemque principis apostolorum amorem, de sue hereditatis rebus apud Gothmarum Gerundensis ecclesiae presulem cum consensu tam clericorum quam laicorum praedictae sedis regulariter firmiterque comutaverat, ut moris est, ea scilicet ratione inibi regula beati Benedicti cum abbate proprio exerceretur». CC, II, p. 78

Hispania, LXI/2, núm. 208 (2001) 417-448 
Reims para rogar a Luis IV de Ultramar que acogiera al monasterio bajo su protección ${ }^{39}$. En este caso se trata de la última concesión del privilegio de inmunidad para un monasterio catalán, pero no es la última vez que una dignidad condal se dirige a la autoridad regia. En este sentido hay que mencionar la confirmación de bienes concedida en 981 por el rey Lotario al monasterio de Sant Genís Les Fonts, destruído unos años antes por incursiones islámicas (quod olim a paganis destructum fuit), la cual estuvo precedida por los ruegos escritos de Gausfred, duque del Rosellón: «quemadmodum domnus Goifredus, dux Rossilionensis pagi, litteram transmiserit ad nostram clementiam». Ello demuestra para fechas muy tardías la vigencia del papel del monarca como patrono del cenobio en virtud de la antigua relación de dependencia generada en 819 con la concesión del privilegio de inmunidad ${ }^{40}$.

Todos los ejemplos de este apartado registran la autoridad de la monarquía carolingia en los condados catalanes en la segunda mitad del siglo $\mathrm{X}$, la cual se posibilitó no sólo merced a las diversas solicitudes de las instituciones locales sino que, como se ha visto, también de los propios intereses de la monarquía. Así, en las renovaciones del privilegio de inmunidad concedidas a los monasterios de Sant Cugat del Vallès y a Santa María de Ripoll, el monarca confirma los bienes de ambos monasterios a cambio de que los defiendan en su nombre «in nomen nostrum defendant». Se traten ambos documentos de reconstrucciones hechas por Ramon d'Abadal, lo cierto es que esta indicación regia aparece inscrita y es importante destacarla pues no deja de ser un elemento más que contribuyó a mantener la autoridad regia en los condados catalanes. A lo largo de este apartado se ha tratado de destacar esta constatación frente a la que desarrollaremos a continuación en la que se describirá la relación de los establecimientos monásticos con el ascenso de los poderes locales, ascenso que no comportó en ningún caso el olvido de la dinastía reinante en el territorio escogido.

\subsection{El nuevo marco de acción condal. Tradición y novedad}

En paralelo a la permanencia de la autoridad regia en la segunda mitad del siglo $\mathrm{X}$, las diferentes dignidades condales del reino fueron asumiendo cada vez mayores competencias religiosas procurando así vertebrar la organización territorial de sus condados. La elección de los establecimientos eclesiásticos como conducto de esta política no podía ser más acertada puesto que éstos se estaban consolidando en esta época como instituciones óptimas en este sentido dada la enorme precisión de su alcance social ejercido a través de la percepción de los

\footnotetext{
39 «Unde nostrae altitudinis munificentiam satis reverenter expetiit quatenus praedictum coenobium nostrae ditioni omnino vendicantes cum omnibus juste sibi pertinentibus nostrae regalitatis praecepto confirmare dignaremur». CC, II, p. 78.

40 CC, II, pp. 206-207.
} 
principales censos parroquiales, los diezmos y las primicias. De esta manera, los condes no sólo afianzaban su poder político y social dentro de sus condados sino que además facilitaban por otra parte su intervención en otros ámbitos territoriales próximos. Estas maniobras se sancionaron con un progresivo acercamiento al papado, el cual emerge ahora como una institución superior capaz de garantizar la articulación en el plano eclesiástico de las nuevas aspiraciones territoriales de los condes y con el que se evitaba el dictamen de los concilios provinciales, en cuyo marco tradicionalmente tenía lugar la resolución de los problemas relacionados con la organización eclesiástica.

La nueva colaboración con el papado se concretó desde sus inicios en la concesión de bulas pontificias para antiguas (Sant Miquel de Cuixà, Santa María de Ripoll, Santa María d'Arlès) y nuevas fundaciones religiosas (Sant Benet de Bages). En ellas se les concedía o confirmaba el viejo privilegio de inmunidad, estableciéndose de alguna manera por vez primera la protección romana sobre las mismas. Como es lógico, esto dió lugar al desarrollo de un nuevo marco de relaciones entre las instituciones condales y las instituciones religiosas locales diferente al del período anterior que estuvo más definido o caracterizado por el patrocinio de la monarquía carolingia sin que éste, como se ha podido comprobar, haya terminado de desaparecer. En este sentido, desde la segunda mitad del siglo $\mathrm{X}$, en el comportamiento de los condes, se observan elementos tradicionales - recurso a la monarquía carolingia - y otros novedosos — desempeño de mayores competencias religiosas, recurso al papado- a través de los cuales se repasará la transición hacia el patronato pontificio.

La simultaneidad de estos elementos define la fluídez de unos años en los que se detectan tres niveles en la acción condal y a los que se acaba de hacer alusión. El primero de ellos se caracteriza por la obtención de privilegios regios de inmunidad en un marco de colaboración con la monarquía y del que ya nos hemos ocupado; el segundo de ellos se refiere a la asunción de antiguas competencias regias de índole religiosa por la autoridad condal que comportó la concesión de amplias libertades a diferentes casas monásticas; el acercamiento al papado completa el nivel anterior y surge de la necesidad de la sanción de una autoridad eclesiástica superior que ratificara los cambios y adaptaciones introducidas por los condes en las estructuras eclesiásticas a fin de reforzar su propio proceso de expansión territorial en el contexto político de emergencia de los llamados Principados Territoriales.

Con el fin de agilizar la explicación de la materia que se va a tratar en esta parte del presente trabajo, su explicación se estructurará en varios subapartados coherentes con los niveles ahora descritos. Como ya se ha tratado el relativo a la pervivencia de la tradición carolingia, se empezará por estudiar la política condal sobre los centros religiosos y que será completado con otro apartado específico destinado a analizar el acercamiento de los condes catalanes al pontificado de Roma, y que abre las puertas de un nuevo período (s. XI). 


\subsection{La asunción condal de competencias religiosas}

Con la gradual acaparación de competencias religiosas, condes y magnates consiguieron aumentar su participación sobre las instituciones eclesiásticas locales y mejorar dentro de sus ámbitos territoriales sus respectivas posiciones sociales y canalizarlas además hacia otros condados vecinos. Esta política se sancionó con un acercamiento al papado, que en este sentido favoreció la superación el tradicional marco conciliar en donde tenía lugar la resolución de problemas relacionados con la organización eclesiástica. Pero por el momento nos ceñiremos en este punto al estudio de las estrategias utilizadas por los condes para ampliar su participación en las comunidades monásticas así como al repaso de algunas manifestaciones significativas de las nuevas competencias religiosas que se arrogaron y que definieron su actuación política entre finales del siglo $\mathrm{X}$ y comienzos del XI.

Con el fin de aumentar su participación en los monasterios, los condes siguieron donando y dotándolos o bien aumentando su dominio sobre el cargo abacial. Este intervencionismo sobre los centros religiosos no es algo nuevo en sí puesto que en la documentación anterior, privilegios carolingios incluídos, se detectan algunas noticias al respecto, donaciones y dotaciones de templos sobre todo $^{41}$. Lo que sí es más original de esta época en cambio son los efectos que éstas empiezan a comportar y que en adelante se explicarán por separado a pesar de obedecer todas ellos a los deseos de los condes por estrechar sus vínculos con los centros monásticos.

Son numerosas las cartas de donación que para todo el ámbito catalán se percibe en esta época. Este incremento de donaciones de bienes inmuebles a centros monásticos lleva a pensar que en esta época éstas se habían constituido o consolidado como uno de los medios más eficaces para aumentar la participación condal sobre las mismas. Así por ejemplo en 979, Miró III, conde de Besalú y obispo de Girona, condicionaba la donación de un alodio en Taià de Serinyà al monasterio de Banyoles a la necesidad de la comunidad monástica de seguir rigiéndose bajo la regla benedictina ${ }^{42}$. Como se comprueba, la donación es en este caso un medio que permite al conde aumentar su control sobre los

41 Respecto a las dotaciones de monasterios son muy buenos ejemplos el segundo documento del monasterio de Ripoll (938) y el tercero de Sant Cugat del Vallès (986) en los que se indica que el circuito alodial alrededor del cenobio fue concedido, en el primer caso por el conde Wifredo el Velloso (880) y en el segundo por Sunyer de Barcelona. Respecto a las donaciones de iglesias sería más farragoso ofrecer aquí una lista detallada de todas las referencias existentes, pero basten citar para ello los privilegios del monasterio de Sant Pere de Rodes o los de Cuixà y Ripoll.

42 «Omnia igitur praescripta trado vel concedo ad praefatum coenobium propter remedium animae Domini Seniofredi fratris mei vel animae meae, ut tam praesens Abbas vel monachi ibidem Deo militantes quam et succesores sui suorumque inrevocabili ordine praedictum alaudem teneant possideantque secundum institutionem beati Benedicti sine alicujus minoratione vel contradictione». MARCA, Petrus de: Marca Hispanica sive limes bispanicus, Paris 1688 (ed. facsimil, Barcelona 1990, en adelante abreviado como MARCA) ap. 126. 
monjes de Banyoles concretado en el cumplimiento de la regla benedictina, tarea que tradicionalmente les estaba siendo vetada.

La intensificación de las donaciones condales estuvo además muy favorecida o respaldada por la nueva mentalidad religiosa que planteaba la necesidad de conceder limosnas a la Iglesia como condición indispensable para la salvación de su alma en el Juicio Final. Son muchos los ejemplos que han quedado en la documentación catalana. Así, en el testamento del conde Sunifredo II de Cerdaña se contemplan referencias al Antiguo Testamento como justificaciones de sus donaciones (966): «eo quod memor sum illius veri proverbiii quod per quendam Salomonem dicentem audivi: Eleemosyna a morte liberat animam, et non permittit operarium suum ire in tenebras» ${ }^{43}$. En la misma línea se expresa en el conde Miró iii Bonfill en la donación del Sant Miquel i Sant Genís de Besalú al papado unos años más tarde (977): «Eleemosyna a morte liberat anima». Junto a las referencias bíblicas se encuentran los propios discursos de los obispos que destacan la obligación de los fieles de alimentar y aumentar el patrimonio eclesiástico. En la documentación reunida para Sant Esteve de Banyoles se encuentra uno de ellos recogido en las actas de reconsagración del monasterio en 957. En ellas el obispo de Girona Arnulfo indica que «plurimis operibus satagentes bidentidem ecclesie enutrire et augmentare, non desisterent frequentare» ${ }^{44}$.

Los constantes trasvases de lotes de tierra a los centros religiosos se traducía en la necesidad de los condes de disponer de constantes cantidades de éstas para remunerarlos. Puede ser ésta una de las explicaciones para la relativa abundancia de noticias a movimientos rebeldes y excomuniones que se perciben en estos años y que relacionamos con el interés condal sobre iglesias y monasterios. En 952, Guifré II de Besalú acudió a la corte regia para obtener la confirmación regia sobre la confiscación del «traidor» Unifredo, probablemente vizconde del Conflent ${ }^{45}$. Siete años más tarde, en 957 una revuelta en el condado de Besalú terminó con la vida del conde Guifré ii, la cual repercutió de forma notable en las relaciones entre los condados de Cerdaña, Besalú y Barcelona. Por la confiscación de bienes derivada, pudo Miró III Bonfill repartir en 979 algunos de los bienes de los rebeldes Wigila y Trasovado entre algunos monasterios del condado de Besalú (Ripoll, Sant Esteve de Banyoles) ${ }^{46}$. Estos ejemplos ilustran que en estos años de transformaciones y de ascenso de los poderes condales, las confiscaciones de bienes inmuebles detectadas pudieron estar estimuladas por la necesidad de los condes de disponer de tierras para cederlas posteriormente a los establecimientos eclesiásticos. El traspaso de este tipo de bienes a las iglesias suponía para los condes favorecer su presencia en

\footnotetext{
43 MarCA, ap. CIV, cols. 885-886.

$44 D B, I$, docs. 37 y 37 bis.

45 CC, II, p. 391.

$46 \mathrm{NH}, \mathrm{I}$, ap. $6 ; D B, \mathrm{I}$, ap. 45.
} 
los monasterios beneficiados, ganar adeptos a sus intenciones políticas y eliminar elementos contrarios a sus intereses.

Tan o más importantes incluso que las mismas donaciones son las dotaciones de las nuevas fundaciones religiosas. Como ya se ha advertido más arriba, ésta era una costumbre que venía produciéndose desde antiguo y sirvan de ejemplo las realizadas por Guifré el Pilós a los monasterios de Sant Joan de les Abadesses (879) y de Santa María de Ripoll (880) o la misma dotación del circuito alodial del monasterio de Sant Cugat del Vallès por el conde Sunyer de Barcelona a mediados de siglo $\mathrm{X}^{47}$. No obstante, en adelante, las cartas fundacionales de los monasterios más recientes conceden amplias libertades que en definitiva equivalen al privilegio regio de inmunidad. Son por tanto documentos muy interesantes para estudiar las relaciones emergentes entre el poder condal y el eclesiástico a finales de la décima centuria. Abadal ya puso esta situación de relieve para los monasterios de Sant Benet de Bages (972), Santa María de Serrateix (977), Sant Pere de Besalú (977) y Sant Llorenç prop de Bagà $(983)^{48}$. Este es un aspecto novedoso en cuanto plasma la asunción por parte de los condes de unas competenecias de tipo religioso que anteriormente no pudieron ejercer o que al menos de ello no ha quedado constancia escrita. El caso de Santa María de Serrateix es uno de los mejores ejemplos en tanto en cuanto su acta de consagración es un fiel reflejo del proceso de instauración del poder condal sobre el monasterio y por tanto válido para demostrar lo que aquí se está sosteniendo.

Santa María de Serrateix (diócesis de Urgell) fue consagrada por primera vez en 977 por el obispo Guisad de Urgell en compañía de los condes Oliba Cabreta y su hermano Miró III Bonfill, condes de Cerdaña y Besalú respectivamente. El templo estaba levantado en tierras de éstos («infra terminos de ipso nostro dominio") en el pagus de Berga, cuya jurisdicción civil pertenecía a los condes de Cerdaña-Besalú, aunque la eclesiástica recaía en manos de los obispos de Urgell ${ }^{49}$. Este dato da cuenta ya de la intención de los dos hermanos por proteger vía eclesiástica su dominio territorial inscritos en otros ámbitos territoriales ajenos a su jurisdicción. Para proteger a la nueva fundación, los condes intervienen de forma directa en la construcción de la iglesia, iniciativa en un principio del monje Froilà y de otros «hermanos suyos» (cum aliis suis fratriiis) $)^{50}$.

\footnotetext{
47 «In primis ipsum alodum quod in circuitu ipsius coenobii est, sicut Suniarius comes concessit et terminavit». CC, II, p. 198.

48 ABADAl I VINYAls, Ramon d': Els primers comtes catalans, Vicens-Vices, Barcelona, 1961, pp. 299-300.

49 «Igitur nos suprascripti volumus notum fieri et manifestate omnibus bominibus de supradicta Ecclesia vel coenobio, quae est situ in comitatu Bergitano infra terminos de ipso nostro dominio". MARCA, ap. CXXII, col. 914. El documento completo se encuentra en MARCA, ap. CXXII, coll. 914-916.

so «Nos autem suprascripti quando audivimus et vidimus aedificare ibi Ecclesiam à domno Froylane monacho cum aliis suis fratribus, id est, Godemarus Presbyter et monachus et Armamirus Presbyter et monachus, et Ildesindus monachus, et Lodoici monachus, et Ausaloni monachus et Signifredi monacbus, ego Oliba Comes et
} 
Seguidamente, Oliba Cabreta y Miró III regulan la elección del cargo abacial, instituyendo ellos mismos como primer abad al mismo Froilà y decretando a su vez que sus sucesores debían ser miembros de la comunidad monástica, recibir la fidelidad de la misma y disponer del consentimiento de los condes, del obispo y del de los propios monjes. En caso de que ninguno de ellos fuera válido para ocupar el cargo, podrían, acompañados por la nobleza local buscar como patrono a otro cargo de otro monasterio que tendría que ser eso sí confirmado por el obispo de Urgell y por los condes de Berga ${ }^{51}$. Para conservar todos los derechos que tenían en dicho condado, los condes los donan al monasterio además de la parroquia de Serrateix junto con los censos que ahí se percibían (los parroquiales - diezmos y primicias- además del censum y la tasca ${ }^{52}$. Posteriormente regulan otras facetas de la vida monástica (el consumo cotidiano de una libra de pan de acuerdo a la regla benedictina además de legumbres, aceite y vino), y convierten a la casa de Serrateix en iglesia mayor del condado. Esto da muestra de hasta qué punto los condes fueron capaces de conceder estas medidas sin consentimiento alguno de los concilios provinciales, instituciones a las que competía estas funciones. Finalmente, conceden a la casa el privilegio de inmunidad, en una demostración de su asunción de competencias regias: «Et ipsum praescriptum coenobium usque in finem seculi sita liberum et francum et cum nimis libertate et cum suo proprio Abbate et de sua congregatione sicut est scriptum in regula sancti Benedicti. Et nos donatores, neque Episcopi, neque nullus Comes qui post nos futuri advenerint, non habeant licentiam mittere ipsum monasterium neque sua honore in nulla subjectione de nullo alio coenobio neque de nulla Ecclesia... et nullus Comes neque Episcopus non sit ausus dare ipsum coenobium per feudum ad nullum hominem».

domnus Mironus Episcopus frater meus quaesivimus consilium à domno Vuisado Episcopo sedis Vrgelllitanae, et per adjutorium et nostrum et consilium Dei et nostrum et consilium domni Vuisadi Episcopi construximus ibi monasterium ad habitandum monachos in honorem Sanctae Mariae».

51 «et elegimus ibi Abbatem et patronum domnum Froylanem Abbatem, qui prius fuit monachus et fundator de praedicta Ecclesia... exceptam ipsam electionem de omnibus Abbatibus qui post ipsum futuri advenerint, non sit facta sine consensu et consilio nostro et nostris successoribus et de Episcopo sedis vici Vrgellensi et de monachis ibi babitantibus; et de illorum congregatione eligatur ipse Abbas, si talem invenire possint qui siat fidelis in bunc locum; et de omnibus bominibus... fidem debet babere et tenere. Et si in bunc locum non possint invenire talem, ipsi monachi cum nobilibus viris Bergitanis inquirant patronum ad alium coenobium qui siat bonum contra... et intra monachos ejusdem loci, et eligant eum ap. con. Episcopum Vrgellensem et Comites Bergitani».

52 «Donamus nos suprascripti, ego Olibane et Mirone Episcopus frater meus ad supradicta Sancta Maria sive ad ipsa Ecclesia quae est fundata in ipsa serra de Texo, et ad Froylane Abbate et ad suos monachos ibi babitantes et ad omnes Abbates et monachos qui babitant in bunc locum, et post transitum de ipsis qui bodie babitant ibi, ipsa nostra parrochia de serra de Texo quae est in nostro dominio, totum ad integrum cum suis terminis et affrontationibus et introitibus et exitibus earum, cum decimis et primitiis, et tota omnia, et tascas et defunctionibus et totum censum qui inde debet exire, et omnes plantas cum ipsiis bestiis, cum silvis, garriciis, pascuis, aquis aquarum fontes et torrentes et aquas ad molendinos ex omnibus partibus cunctisque locis ubi potest bomo aedificare molendina ad opus Sanctae Mariae, sive in Chadernario et in omnibus aquis qui sunt in pago Bergitano. Et tota omnia quae ullus Comes debet habere in suo bonore et nos babemus in ipso nostro dominio, totum donamus sanctae Mariae et domno Froylane Abbate et suis monachis ibi cum eo commorantibus, sine ulla retentione quam ibi non faciamus».

Hispania, LXI/2, núm. 208 (2001) 417-448 
El control sobre cargos abaciales fue otro de los objetivos de los condes en el desempeño de nuevas actuaciones políticas y era resultado del incremento de la política condal sobre las comunidades monásticas. Baste mencionar el que en 961 el conde Sunifredo II de Cerdaña encargó a Garín, abad entonces de San Pedro de Lézat, la dirección de Sant Miquel de Cuixà, cenobio sujeto a la dependencia regia y que disponía del derecho a la libre elección de abad tal y como se ordenaba en los cánones de la regla benedictina ${ }^{53}$. De la misma forma, en 977, el mismo año en que es consagrada la iglesia de Serrateix, Miró III de Besalú, haciendo lo propio con el altar de Sant Rafael en la iglesia de Sant Vicenç de Besalú permite que la condesa Ermengarda junto con su hijo Bernardo dispusieran del derecho a instituir canónicos regulares ${ }^{54}$. Instituyen que el puesto de rector lo ejercieran los canónigos en otra clara actuación de las nuevas competencias religiosas asumidas por los condes y que nos están hablando ya del cambio de época. La intención que entendemos se perseguía con estas medidas era minar poder a los diocesanos, pues como veremos más adelante, el control sobre los mismos se estaba convirtiendo en otra de las fórmulas típicas de intervención de los condes en condados ajenos, aprovechando la disfunción entre la geografía eclesiástica y la laica. Adelantaremos por el momento que en 971, el conde Borrell de Barcelona había conseguido del papa Juan XIII el asentimiento para la creación de un arzobispado en Osona con el fin de tener bajo su influencia a las diócesis del ámbito catalán. De la misma forma, si Miró III Bonfill, conde de Besalú, obtuvo la mitra gerundense fue con toda probabilidad para evitar la injerencia de la casa de Barcelona en el emergente condado de Besalú, inscrito en el territorio de la diócesis de Girona y que por consiguiente no disponía de obispado propio.

\subsection{Los condes catalanes y el papado}

El progresivo recurso condal al papado en la segunda mitad del siglo $\mathrm{X}$ es consecuencia de la política emprendida por éstos en materia eclesiástica en esta misma época. Con la obtención de bulas pontificias para los diferentes monasterios, los condes sumían a las diferentes casas monásticas bajo la protección romana y culminaban así una política que poco a poco les afianzaba en sus

53 Los antecedentes directos se encuentran tanto en el modelo cluniacense de monacato como en la reforma monástica que al norte de los Pirineos fomentaba el conde Roger de Tolosa a través de la figura de Garín, abad desde 961 de San Pedro de Lézat, monasterio no lejano a Foix e inserto espiritualmente en la órbita cluniacense desde al menos veinte años antes. ABADAL I VINYALS, Ramon d': «Com neix i com creix un gran monestir pirinenc abans de l'any mil: Eixalada-Cuixà», Analecta Montserratensia, VIII (1954-1955) pp. 125-337.

54 «ut Ermengarda jam nominata Comitissa et filius ejus Bernardus statuant ibi canonicos regulares ui die et nocte Deo deservint et orent misericordem Dominum pro delictis meis atque pro cunctis fidelibus defunctis.». MARCA, ap. 121. 
condados. Cumplían con ello la articulación territorial de los condados por medio de las instituciones eclesiásticas y la reestructuración de su red. Surge así la necesidad de la sanción del papado que abría la posibilidad de alternar o evitar los antiguos marcos conciliares en donde se solventaban los problemas relacionados con la organización eclesiástica. Con anterioridad la sede de Roma gozó de cierta primacía honorífica que le confería un poder último de decisión en casos relativos a la jerarquía eclesiásticas ${ }^{55}$. Pero esta primacía estaba cambiando en el último tercio del siglo $\mathrm{X}$. El papa va adquiriendo poco a poco un mayor protagonismo en el ámbito catalán y es recurrido por los condes para sancionar las medidas de índole religiosa que éstos estaban aplicando en sus condados y que, repetimos, eran competencia de los concilios provinciales.

\subsubsection{El papado y los monasterios}

Sant Miquel de Cuixà es el primer monasterio del ámbito catalán sujeto a la tuitio pontificia. En 950 su monje Sunyer recibió de Agapito II una bula en la que el papa acogía al establecimiento bajo su protección («et securis atque quietis sub norma et apostolica tuitione permanendo" $)^{56}$. Sin embargo, es al año siguiente cuando ya se tiene la primera noticia de la presencia de un conde del ámbito catalán en la corte romana solicitando del papa privilegios pontificios similares para otros monasterios. Se trata del viaje organizado por Sunifredo II de Cerdaña acompañado por los abades Hildesindo de Sant Pere de Rodes, Arnulfo de Santa María de Ripoll, del obispo Guisad de Urgell y del noble Sal.la, fundador del monasterio de Sant Benet de Bages, (condado de Osona-Manresa). Las bulas concedidas repetían a grandes trazos el modelo de los anteriores privilegios carolingios, y asentaban el patrocinio pontificio sobre las casas beneficiadas, a pesar de faltar la cláusula específica que lo afirmara de forma explícita como en el privilegio de Sant Miquel de Cuixà del año anterior ${ }^{57}$.

5s De este tipo son los tres documentos pontificios más antiguos conservados para las diócesis catalanas, que datan de finales del siglo IX. Uno del papa Formoso (893), dirigido al obispo Servus Dei de Girona quien acudió a Roma «causa orationis» y dos del papa Romano (897). De estos dos últimos, uno de ellos está dirigido al mencionado obispo de Girona, a quien se le justifica al frente de su cargo frente al intruso Ermemir, y otro al obispo Riculfo de Elna. KeHR, P.: «El papat i el Principat de Catalunya fins a la unió amb Aragó», Estudis Universitaris Catalans, 12 (1927), p. 326.

56 «Igitur quia Soniarius religiosus Presbyter et monacbus vice vestra ante nostram praesentiam veniens postulavit a nobis quatenus confirmaremus tibi tuisque successoribus Abbatibus... et securis atque quietis sub norma et apostolica tuitione permanendo" MARCA, ap. 87, coll. 864-865.

57 «Ut nullus Rex, nullus Princeps, nullus Comes, nullus Marchio, nulllus Judex neque ulla magna parvaque persona aliquod damnum aut invasionem in eodem coenobio neque in suis pertinentiis unquam facere praesumat» MARCA, ap. 88, coll. 866-867 (Urgell); «Ut nullus Rex, nullus Princeps, nullus Comes, nullus Marchio, nulllus Judex neque ulla magna parvaque persona aliquod damnum aut invasionem in eodem coenobio neque in suis pertinentiis unquam facere praesumat». En este privilegio el papa trata de establecer su patronato sobre el cenobio prohibiendo la compraventa del cargo abacial por magnates laicos sean

Hispania, LXI/2, núm. 208 (2001) 417-448 
A partir de entonces los contactos de los condes de Cerdaña con la sede romana se multiplican. En 968 el conde Oliba Cabreta acude a Roma y consigue que el papa Juan XIII acoja bajo su patrocinio al monasterio de Santa María d'Arles (Vallespir). El papa en su condición de señor del centro regula el ámbito de la acción condal en el mismo permitiendo de forma extraordinaria que, en caso de que el abad se comportara de forma indebida, el conde pudiera expulsarlo y poner a otro en su lugar. Este control condal sobre el cargo abacial responde a la vinculación que desde su misma fundación tuvo el centro con la casa de Cerdaña pues fue levantado por el tío abuelo del conde ${ }^{58}$. En este mismo año y presumiblemente con el fin de liberarse de la expansión territorial y presión política de sus familiares condes de Barcelona, se enfeuda a sí y a sus hijos con el papado ${ }^{59}$.

En el condado de Besalú - - en donde estaba Sant Esteve de Banyoles- la «idea de Roma» se difundió a partir del mandato de Miró III Bonfill, hermano de Oliba Cabreta de Cerdaña y sin duda alguna uno de los gobernantes centrales de estos años. A pesar de haberse iniciado en la carrera eclesiástica, destacó por su condición de conde cargo que acogió en 968 y desde donde demostró una considerable habilidad política. Su actuación se centró en el desarrollo de todo tipo de estrategias políticas para consolidar de forma definitiva al antiguo y ambiguo pagus de Besalú convertido en condado autónomo y libre de la influencia del de Girona. Este proyecto le permitió cristalizar su poder frente a los condes de Barcelona que siéndolo a su vez de Girona estaban ejerciendo un fuerte control sobre su sede episcopal en cuya diócesis estaba inscrito el nacien-

reyes o condes: «Statuimus autem ut quando Abbas ipsius coenobii de boc seculo migraverit, neque a Regibus neque à Comitibus neque à qualicunque persona pro cupiditatis pecuniae causa neque pro qualicunque favoris inanis gloria ibidem Abbas sit constitutus». MARCA, ap. 89 (Ripoll).

58 «Oliba Cabreta Comes Cerrateniensis Romam oratum profectus est ad beatissimorum Apostolorum Petri et Pauli sacratissima corpora; eaque occasione obtinui a Ioanne Papa XIII. uti monasterium Arulense, quod a fratre avi sui constructum fuerat, sub ditione atque tuitione sedis apostolicae poneretur». MARCA, col. 400 . Sobre la petición del conde al papa y de la protección de éste sobre el monasterio: «Et ideon sciat omnium vestrorum bonitas atque industria quia vir deum timens et inclitus Comes nomine Oliba veniens oratum Romam ad beatissimorum Apostolorum Petri et Pauli sacratissima corpora postulavit a nobis, ut monasterium quod vocatur Arulas, constructum à fratre avi sui ad bonorem Domini de semper virginis Dei genitricis $M a-$ riae, positum territorio comitatus Rossilionensis, in loco qui vallis Asperi vocatur, juxta ripam fluminis Theti... sub perpetua immunitate sanctorum patrum cum defensione sanctae nostrae sedis apostolicae manendum decerneremus cum omnibus rebus et possessionibus sibi pertinentibus... Statuimus id ipsum Dei genitricis monasterium ex integro pro sua stabilitate perpetualiter ad ditionem atque tuitionem sanctae Matris Ecclesiae persisti debere, confirmante illi omnes res quae jure et rationabiliter sibi a principio pertinent... sub protectione nostrae sedis apostolicae perpetuis temporibus à praesenti XII. Indictione». "Dicimus etiam ut Abbas qui ibidem pro tempore fuerit, si, quod absit, a regulari proposito et institutione beati Benedicti deviaverit, sive res monasterii ejusdem alienaverit, licentiam babeat praedictis Comes Oliba sive sui eundem Abbatem expellendi foras et quod ab eo alienatum fuerit ad proprium jus revocandi et pro ipso alium Deo dignum Abbatem constituendi, approbara rei veritate». MARCA, ap. CX, coll. 893-894.

59 JUNYENT SUBIRÀ, Eduard: Diplomatari $i$ escrits literaris de l'abat $i$ bisbe Oliba, Institut d'Estudis Catalans, Barcelona, 1992, doc. 10, pp. 16 y ss.

Hispania, LXI/2, núm. 208 (2001) 417-448 
te condado de Besalú. Para acabar con este problema Miró III alcanzó el titulo de diocesano de Girona a la muerte de Arnulfo, no sin ciertas irregularidades, pudiendo así interrumpir momentáneamente el peligroso desarrollo de los lazos de dependencia entre los condes de Barcelona y aquella sede episcopal. Estos planes terminaron de completarse con su supuesta participación en el asesinato de Ató primer arzobispo de Osona y además provisor y administrador de la sede gerundense por concesión del papa Juan XIII a instancias del conde Borrell de Barcelona ${ }^{60}$.

Estos hechos, muestran en qué condiciones estaba dispuesto Miró III a proteger su cargo, - y por extensión su condado- del expansionismo de los condes de Barcelona, a quienes por el momento se les escapaba el control de la sede de Girona y con ello su capacidad de intervención en su ámbito diocesano. Este episodio evidencia a su vez que el control efectivo sobre los obispados era una de las puertas de intervención de los condes de Barcelona en territorios próximos. Es lógico que en consecuencia Miró III contrarrestara esta presión tratando de reducir las competencias de los obispos en los monasterios, instituciones que utilizaban los condes para liderar la organización territorial de sus condados. Por tanto, con este mismo fin, el conde-obispo donó algunas de las iglesias y monasterios más importantes de su condado al papado, no sólo para protegerlas de la intromisión de condes y magnates sino que con ello también «desvinculava les noves fundacions de la futura autoritat diocesana, sotmetent-les directament al papa en propi alou, tot adjudicant-li un cens anual en reconeiximent més o menys simbólic. A Roma, refermà aquestes iniciatives amb sengles butlles papals que confirmaven les clàusules fundacionals $i$, curiosament, Miró Bonfill no recaptà cap privilegi per a la seu de Girona, mostra evident del seu desinterès per a fer-bo" ${ }^{61}$. Entre las donaciones más significativas del conde están la de la iglesia de Sant Vicenç de Besalú, así como la de Sant Pere en la misma villa donada esta última en condición de alodio, ambas concedidas en $977^{62}$. El acercamiento de Miró III al papado era uno de los pasos que estaba obligado a cumplir en su deseo de consolidar su cargo frente a otros condes, los de Barcelona fundamentalmente.

Pero si bien la presencia del nuevo ambiente político-religioso estaba instalándose en el condado de Besalú a finales del siglo x éste no estará plenamente consolidado hasta bien entrado el siglo xi, bajo el gobierno de Bernat I Tallaferro (996-1020) ${ }^{63}$. Su penetración pensamos fue gradual, progresiva, es decir, ni

60 MARTí I CASTElló, Ramon: «Delà, Cesari i Ató, primers arquebisbes dels comptes-prínceps de Barcelona» I Congrès de Història de l'Esglèsia Catalana. Des dels orígens fins ara, Solsona, 1993, p. 378.

61 Martí I CaSTELló, Ramon: op. cit., p. 380.

62 MARCA, ap. CXXI, col. 919; En cuanto a la donación en alodio de Sant Pere de Besalú «et cum scriptis donationis, tradimus Ecclesiae beatissimorum Apostolorum principis Petri Romae ac domini Papa ad proprium alodium, ut sub ejus defensione atque munimine consistat in perpetuum» MARCA, ap. CXXIV, col. 920.

63 Según el profesor Luis García Guijarro, el acercamiento de Miró Bonfill obedecía por vincularse con Roma perseguía un reforzamiento de la autoridad condal: «La doble actuación de Mirón 
homogénea ni uniforme lo que da a entender que no a todos los establecimientos eclesiásticos afectó por igual en un primer momento. En lo que incumbe por tanto a Sant Esteve de Banyoles la primera noticia directa que se tiene de su plena vinculación con Roma data ya de 1017. No obstante, por algunas noticias que tenemos dispersas en los documentos que se han manejado podemos inferir que antes de estas fechas el cenobio ya estaba dentro de la órbita condal desde al menos el gobierno de Miró III.

Así la donación de éste de un alodio en Taià de Serinyà al monasterio de Sant Esteve de Banyoles en 979, como se vió ya anteriormente, estuvo condicionada por la obligación de la comunidad monástica de quedar sujeta a la norma benedictina. Es cierto que no se trata de una cita significativa, pero no por ello podemos pensar en que no hubiera cierto mandato condal, tratándose además de la primera intervención condal registrada en la documentación de esta abadía. De aquí se puede desprender que bajo el gobierno del mencionado conde y obispo la casa de Banyoles estaba ya inserta en el ambiente reformista del momento. Unos cuantos años más tarde, en 1004, Guadamir, abad de Banyoles, aparece formando parte del círculo de consejeros del conde Ermengol I de Urgell, entre los que estaban Ermengol, arzobispo de Narbona, los obispos Sal·la de Urgell ${ }^{64}$, Odó de Girona ${ }^{65}$ y Arnulfo de Vic, además de los abades Sunifredo de Ripoll, antecesor del abad Oliba, y Llobet Benet de Arlés, asesorándole sobre la unión del monasterio de Sant Climent de Codinet con el de Tresponts o Centcelles, situado en Fígols d'Organyà (Alt Urgell), ya que la primera de estas abadías estaba al parecer sumida en un ambiente grave de corrupción ${ }^{66}$. Siendo esta noticia un registro documental no podemos saber los

Bonfill refleja preocupación por mantener la coberencia de las vinculaciones de la sede que representaba. La utilización del poder episcopal para robustecer la posición condal, cuyo fortalecimiento beneficiaría en un futuro a su sobrino Bernardo, de abi la insistencia de éste y de Ermangarda, es comprensible a partir de las dificultades experimentadas por los descendientes de Mirón II para consolidar el dominio feudal sobre Cerdaña, Besalú y enclaves asociados. La inexistencia de obispado propio generaba vínculos foráneos [...] perturbadores de la concentración clarificadora de las dependencias en torno a los condes locales. La sede gerundense [...] sólo podía ser cercenada mediante el recurso tradicional a la sede apostólica. Esta vía fue activada precisamente por Mirón, obispo de Girona elegido por el beneplácito de Borrell II, pero, ante todo, conde de Besalú, propulsor del afianzamiento feudal familiar en los territorios de su dominio». García Guijarro, Luis: Papado, Cruzadas y Órdenes Militares. pp. 444-445 (inédito).

64 Este personaje cobra gran importancia en la vida eclesiástica del momento, ya que fue uno de los elementos más importantes en la introducción definitiva de la reforma cluniacense en Cataluña. En su vida ejerció simultáneamente los cargos de obispo de Urgell y abad del monasterio francés de La Grassa ABADAl i VinYals, L'abat Oliba, bisbe de Vic i la seva época, Aedos, Barcelona, 1962.

65 Este obispo debía guardar unas relaciones bastante estrechas con el conde Ermengol de Urgell, ya que fue uno de los organizadores de la campaña contra Córdoba, en la que murió, junto con el conde. Es por este hecho militar por el que el conde ha pasado a la historia conocido como «el Cordobés».

$66 D B, I$, doc. 52 (regestum). En cuanto al monasterio de Codinet, Abadal opina que . «totes les possessions $i$ tots els predis del monestir eren alienats $i$ venuts, els llibres perduts $i$ espargits [...] el papa li respongué que faria un gratíssim servei a Crist, si aquells que es diuen monjos $i$ exerceixen negocis seculars, els tornés a 
motivos que propiciaron esta relación del abad de Banyoles con el conde de Urgell y no con el de Besalú como hubiera sido lo esperado. Fuera el conde que fuera, lo cierto es que parece evidente que en Banyoles ya estaba implantado el ambiente de reforma, y que su vinculación con el papado no debía estar demasiado lejos.

Ésta se produjo unos pocos años más tarde, en 1017, con motivo del viaje del conde de Besalú Bernat I Tallaferro a Roma para negociar con el papa Benedicto VIII la instauración de un obispado independiente en su condado, episodio que se estudiará con atención más adelante. En estas vistas, el papa concedió al abad Bonfill de Sant Esteve de Banyoles una importante bula similar a la que en 1011 entregó Gregorio v a los monasterios de Sant Miquel de Cuixà y de Santa María de Ripoll y en las que por primera vez se contemplaban los privilegios de exención apostólica, esto es, la consagración de abad por un obispo libremente escogido por la comunidad («damus quoque licentiam ipsius loci abbati ubicunque vel a qualibuscunque voluerit Episcopis suos clericos ordinandi, a qualicunque sede et placuerit chrismam accipiendi») y la liberación de la asistencia al sínodo diocesano ("Concedimus quoque Abbati vel monachis et omnibus clericis ad monasterium pertinentibus licentiam, nisi voluerit spontaneè vel rogati ad synodum non eundi») ${ }^{67}$. En ambas cláusulas queda manifiesta la total marginación del diocesano en el ámbito monástico, marginación que se completa con la renovación del privilegio de inmunidad, la libre elección de abad, la prohibición al prelado local de ejercer la facultad de excomunión y de interdicto ${ }^{68}$, la protección del dominio monástico ${ }^{69}$, y la libre participación de excomulgados en actividades litúrgicas mientras estuvieran en el recinto monacal ${ }^{70}$.

Las disposiciones de la bula de 1017 son tajantes y no admiten discusión alguna en la admisión de la nueva dependencia del monasterio con el papado, dependencia que tiene lugar dentro del contexto de reforzamiento de la autoridad condal en Besalú. Así, la revitalización del viejo privilegio de inmunidad impedía la intervención de los condes en el propio monasterio, con lo que se anulaba en consecuencia la posibilidad de generación de cualquier lazo de dependencia entre ambos, y no sólo de los condes sino también de los propios magnates. No obstante, aún el papado no había desarrollado los elementos institucionales necesarios para cumplir con este mandato, de tal forma que

\footnotetext{
reunir $i$ els fes viure en comú $i$ segons la Regla de Sant Benet». ABADAL I VINYALS, L'abat Oliba $i$ la seva época, en Dels visigots als catalans, II, pp. 155.

67 Ambas cláusulas en MARCA, ap. 174, coll. 998-1002.

68 «et ut a nullo Episcopo, nec ab illo in cujus situm est monasterium episcopio, nec ab alio possit excomunicari vel aliqua ad eundem monasterium pertinens Ecclesia».

69 «Confirmamus igitur et stabilimus amodo ut nullus Rex, nullus Princeps, nullus Marchio, nullus Comes, nullus Judex, nullus Episcopus, neque ulla magna parvaque persona aliquam vim vel invasionem in eodem coenobio aut in suis pertinentiis facere praesumat».

70 «Statuimus etiam ut quis poenitens a liminibus exclusus Ecclesiae, quandiu ibi steterit, babeat licentiam introeundi et omne divinum officium audiendi»
}

Hispania, LXI/2, núm. 208 (2001) 417-448 
entrado el siglo XI, el monasterio caerá en manos laicas siendo objeto de disputas entre las aristocracias locales - concretamente de los señores de Porqueres, vasallos de los condes de Barcelona-y los propios condes de Besalú.

\subsubsection{El papado y las sedes episcopales}

En la nueva relación de las sedes episcopales con el papado es en donde mejor se advierte las pretensiones condales de expansión por otros territorios condales vecinos merced a las discordancias territoriales existentes entre la administración civil y la eclesiástica. Uno de los casos más significativos fue el nombramiento de Ató como arzobispo de Osona por el papa Juan XIII a instancias del conde Borrell de Barcelona (971) y que a nuestro entender fue producto del plan de los condes de Barcelona por generalizar su supremacía sobre el conjunto de los territorios condales. Pero este no fue ni mucho menos el primer intento de condes catalanes de creación de una sede metropolitana en su ámbito. En este sentido esta política se remonta ya a finales del siglo ix cuando se encuentra la primera tentativa conocida con la irrupción de Esclúa como obispo de Urgell (887-890), que tuvo lugar en unos años críticos en las relaciones de los condes catalanes con el trono franco a raíz del cambio dinástico ocasionado con la entronización del robertino Eudes tras la muerte de Carlos el Gordo (888). Esclúa, religioso potentado de la Cerdaña, fue consagrado obispo por dos prelados gascones. Abadal sospecha que en esta operación debió tener algo que ver el conde Ramón I de Pallars-Ribagorça por sus orígenes gascones. En 886 expulsó Esclúa a Ingoberto, obispo legítimo de Urgell y se hizo con la titularidad de la sede episcopal, contando de nuevo con el apoyo tácito de los condes Ramón I de Pallars-Ribagorza y de Guifré I de Barcelona, Cerdaña y Osona, puesto que ambos tenían buena parte de sus bienes patrimoniales extendidos por aquella diócesis. El intruso también debía ser conocido por el conde de Barcelona ya que el año anterior vendió a este último el castillo de Montgrony (885). Abadal supone que la complicidad de los dos condes ante la usurpación escondía el apoyo que esperaban de Esclúa para la materialización de sus respectivos proyectos. Por una parte a Ramón I se le facilitaba la tarea de erigir un obispado propio en sus condados mientras que Wifredo el Velloso encontraba en el intruso la autoridad eclesiástica necesaria para acometer con la tarea de repoblación y reorganización territorial de las comarcas centrales y occidentales de Catalunya. En efecto, Esclúa acometió la reorganización de la red parroquial de su diócesis — creación de la parroquia de Valltarga, (891) — y ordenando el propio patrimonio de su Iglesia ${ }^{71}$.

Sin embargo, los hechos cambiaron de signo con la muerte de Teutario, obispo de Girona (887). La elección de Servus Dei, clérigo narbonés que al pa-

71 ABADAL I VINYALS, Ramon: Els primers comtes catalans, Barcelona, 1958, pp. ---

Hispania, LXI/2, núm. 208 (2001) 417-448 
recer disponía de buenas relaciones con Teodardo, arzobispo de Narbona y de Wifredo el Velloso, abría las puertas a éste último para intervenir de alguna manera en los condados costeros de Girona y Empúries gobernados por los hermanos Delà y Sunyer II, e inscritos en el territorio diocesano ${ }^{72}$. Éstos por su parte no estaban dispuestos a admitir este estado de cosas. Frente a la alianza amenazadora Teodardo-Guifré-Servus Dei, Sunyer II recaba de inmediato el apoyo de Esclúa, quien aprovechó el acercamiento del conde para arrogarse facultades de metropolitano nombrando a Ermemir como obispo de Girona y a Adolfo como obispo de Pallars-Ribagorça. Para evitar la resistencia del resto de los obispos, atrae a sus planes a Gotmar de Osona y a Frodoí de Barcelona prometiéndoles el puesto de coprovinciales con potestad para nombrar obispos. En 888, los condes de Girona y Empúries juraron fidelidad a Eudes, primer rey robertino tras la muerte de Carlos el Gordo (888), para a continuación el conde Delà entrar por las armas en la ciudad de Girona, expulsar a Servus Dei, e instalar en ella a una comunidad judía. Al año siguiente, el obispo Ermemir y el conde Sunyer II acuden a la asamblea de Orleans y ratifican su fidelidad al nuevo monarca, quien en compensación concede unos generosos privilegios regios a las instituciones eclesiásticas fieles a su persona, - la sede de Vic, al monasterio de Sant Pere de Rodes, al monasterio de Fontclara y a algunas personas en particular - restando con ello potestad y derechos a los condes y monasterios proclives o defensores de la dinastía carolingia. La situación se inclinaba a favor de los de Empúries.

Vista que la situación no podía ser peor para su cargo e intereses, el arzobispo Teodardo viaja en 890 a Orleans y jura fidelidad al nuevo monarca, quien le concede un privilegio confirmatorio de los derechos fiscales de la sede, junto con nuevas propiedades fiscales y por supuesto la protección real. Poco después, Wifredo ya reconoce al nuevo monarca como se plasma en la datación de la iglesia de Sant Pere de Ripoll. Con el monarca a su favor, Teodardo se dispuso de inmediato a deshacer toda la obra de Esclúa y de los condes de EmpúriesGirona. Estas se resolvieron en tres concilios. En el de Port (890), tuvo lugar la comparecencia del obispo Gotmar de Osona, quien aceptó dirigir una legación para convencer al conde Sunyer II, además de restituirse a Ingobert como obispo de Urgell. En el de Mehun-sur-Loire (891) se procedió a la restitución de Servus Dei y finalmente, en el de Urgell (892) a la condena de Esclúa.

Tras los "pintorescos» nombramientos arzobispales de Delà de Girona (951) y Cesari de Montserrat (951-953), no vuelve a haber un nuevo intento programado hasta el encumbramiento de Ató de Osona como arzobispo de aquella sede en 971 . Este nombramiento guarda sus causas principales en el intento de los condes de Barcelona por ampliar su capacidad de maniobra sobre el resto de los condados catalanes a través del control de la sede episcopal de Vic. Como veremos a continuación su proceso fue muy diferente al protagoni-

\footnotetext{
72 MARTí, Ramón: Col•lecció diplomática de la Seu de Girona (817-1100), Lleida, 1997, pp. 75-78.
}

Hispania, LXI/2, núm. 208 (2001) 417-448 
zado por Esclúa, pues a diferencia de éste, fue resuelto con la colaboración pontificia en lugar de en los concilios.

El nombramiento de Ató como arzobispo de Osona se llevó a cabo en 971 cuando el papa Juan XIII a ruegos del conde Borrell de Barcelona concede al beneficiado cinco bulas pontificias en las que se le instituía en el mencionado cargo además de provisor y gobernador del obispado de Girona, cargos estos últimos que según reza uno de los documentos habían sido usurpados en contra de los cánones por un neófito. En opinión del profesor Ramón Martí este neófito no fue otro sino el propio conde de Besalú, Miró III Bonfill quien acogía el obispado de Girona para impedir la injerencia de Ató en el condado de Besalú. Es más, es este estudioso quien insinúa que fue el mismo Miró III quien terminó con el nombramiento de Ató conspirando en el asesinato del metropolitano $^{73}$. La reacción por parte del conde de Barcelona no se hizo esperar y a los pocos días del homicidio entró con su ejército en el condado de Besalú construyendo incluso un castillo en un alodio del monasterio de Sant Esteve de Banyoles. Finalmente, el conflicto finalmente no se llevó a cabo sin que a este respecto haya todavía una explicación clara ${ }^{74}$.

La creación del arzobispado de Osona ejemplifica la intención secular de los condes de Barcelona por ejercer una autoridad total sobre el conjunto de los condados catalanes y que acarreará, vía eclesiástica, enfrentamientos y tensiones entre los titulares de los mismos. Pero si bien la situación aún era inmadura, lo cierto es que, en este sentido, entrado ya el siglo xi había evolucionado notablemente hasta el punto que todos los obispados de las sedes episcopales catalanas estaban ocupados por familiares de la Casa de Carcasona. Este proceso terminó de culminar en 1019 año en el que los condes de Cerdaña compran el cargo arzobispal de Narbona por cien mil sólidos.

Las resistencias a la supremacía de la casa de Barcelona y las disfunciones entre la geografía eclesiástica y la condal - sólo coincidentes en los condados de Barcelona y Osona - motivaron la creación del obispado de Besalú por el conde Bernat I Tallaferro a comienzos del siglo xi, concretamente entre 10171020. Éste, sobrino de Miró iii y heredero directo de su política, trató de afianzar y fortalecer su cargo y su condado frente a las presiones de los condes vecinos, tratando de ejercer un fuerte control sobre las instituciones eclesiásticas. Ello le permitiría dar el salto necesario para la creación de un obispado independiente que le librara de la presión de la casa de Barcelona.

En este sentido, pensamos que detrás la expulsión de las monjas de Sant Joan de les Abadesses y la instalación en la misma abadía de una comunidad de monjes agustinos acaecida en 1011 con permiso del papa, estaba la intención de Bernat I por intervenir de alguna manera en el enorme patrimonio territorial de aquel monasterio y quizá de esta manera poder proveer con sus rentas a

73 MARTí Ramón: v. infra. p. 375.

74 MARTí, Ramón: v. infra. p. 379-380.

Hispania, LXI/2, núm. 208 (2001) 417-448 
la futura sede episcopal bisuldunesa. Resuelto entonces el asunto de la dotación económica, seis años más tarde, acompañado por el abad Oliba, el conde emprende un viaje a Roma (diciembre de 1016-enero de 1017) para que el papa Benedicto VIII resolviese la problemática cuestión del obispado de Besalú.

Tras presentar al papa las tres candidaturas a la sede del nuevo obispado - Sant Joan de les Abadesses, Sant Pau de Fenollet o Sant Genís de Besalú -, el sumo pontífice accedió a la creación del nuevo obispado al que declaraba exento y sujeto sólo a la obediencia pontificia. Nombró como obispo a Wifredo, hijo del conde Bernat, otorgándole además a él y a sus sucesores, que debían ser obligatoriamente abades del «reformado» monasterio de Sant Joan de les Abadesses, potestad para consagrar iglesias, bendecir clérigos y sacerdotes, y ejercer todo el servicio episcopal. El papa se reservaba la consagración personal de los sucesores, exigiendo una libra de oro a cambio de la obediencia. El nuevo obispado escapaba de la influencia de Narbona, ya que se creaba bajo la condición de exento, y sólo como dependiente directo de Roma. Pero al igual que con el arzobispo Ató, la muerte misteriosa del conde cruzando el Ródano a caballo zanjó cualquier intento de continuidad del obispado de Besalú (1020). Wifredo moría el 1054 como obispo de la sede de Carcasona tras conseguir el cargo por la mediación del obispo y abad Oliba, el mismo que se negó a que Besalú contara con un obispado propio, para evitar por una parte la separación del Ripollés, donde está el monasterio de Sant Joan de les Abadesses de la obediencia a Vic, así como la del resto del condado a la Girona ${ }^{75}$. Con estas actuaciones apoyadas en las decisiones del papado se confirmaba el cambio político y se diseñaba el nuevo marco de actuación de los condes en la siguiente centuria.

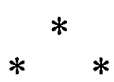

Hasta ahora se ha hecho un breve repaso a una pequeña parte de la historia del monasterio de Sant Esteve de Banyoles durante la Alta Edad Media en lo referido a sus relaciones de dependencia contraidas primero con la dinastía carolingia y posteriormente con el papado. En lo que respecta a la primera de ellas, se ha podido ver como ésta se gestó en los comienzos del siglo IX y se prolongó hasta al menos la mitad de la siguiente centuria. En parte, los más de

75 «Las metas a las que aspiraban los descendientes de Oliba Cabreta parecian baberse alcanzado en su totalidad, pero no sobrevivieron a la muerte de Bernardo Tallaferro en 1020; la diócesis dejó de existir inmediatamente, privada de la defensa de su impulsor ante la acometida de los intereses afectados por el reordenamiento de los límites eclesiásticos. Entre los descontentos debió encontrarse el propio Oliba, favorable en un primer momento a la idea de la nueva sede que apoyó con su presencia en Roma, deseoso más tarde de recuperar las tierras perdidas por el obispado de Vic, que presidió desde 1018. Esta contradicción surgida en el propio círculo familiar antes cobesionado tuvo que ser fatal para la pervivencia de la diócesis creada; el encumbramiento de Oliba a la dignidad episcopal por la condesa Ermesinda pudo tener quizás como uno de sus fines el nacimiento de ese desacuerdo, beneficioso para la Casa de Barcelona, al conducir a la recuperación de los antiguos límites del obispado de Osona estrechamente ligado a aquella», GARCíA GUIJARRO, op. cit. pp. 456.

Hispania, LXI/2, núm. 208 (2001) 417-448 
cien años que duró esta vinculación muestran que la impronta carolingia en Catalunya fue más importante de lo que tradicionalmente se ha venido admitiendo. La relación personal entre el monasterio y el monarca, se generó y concretó a partir de la concesión del privilegio de inmunidad (822), al cual se le puede considerar como la materialización jurídica de esta misma relación personal. A través de ella, las dos partes contractuales pretendían alcanzar unos beneficios recíprocos: el monarca buscaba, a través de la fidelidad de las abadías, imponer y asegurar su autoridad sobre el conjunto de los condados catalanes, cuyas instituciones religiosas, como ya hemos dicho, se mostraron en un primer momento reacias a asumir el programa religioso carolingio. Por su parte, los abades quedaban convertidos en verdaderas instituciones de poder, pues su dependencia directa y exclusiva con el monarca carolingio, hacía de ellos los únicos señores capaces de actuar y dirigir un dominio monástico en plena fase de crecimiento. De la misma forma, los abades, aplicando sobre su dominio monástico los mandatos regios, también se iban convirtiendo en las piezas sobre las que se canalizaba la difusión de la autoridad regia sobre el conjunto de los condados que conformaban la llamada Cataluña Vieja.

Con el privilegio de inmunidad el cenobio y su dominio eran sustraídos de la acción y de la intervención de los agentes ordinarios del rey, pasando a depender exclusivamente del monarca. En consecuencia, el privilegio de inmunidad afectaba a las relaciones que el monasterio tenía contraídas con los agentes del poder público y con el poder diocesano. En lo que se refiere al primer caso, los efectos de éste se traducían en la prohibición que tenían los condes y sus delegados para intervenir en el monasterio, ya fuera en pleitos o exigiendo derechos de hospedaje y avituallamiento militares (paratae, mansiones), y además desde 878 el mansionaticum (derechos relacionados con el hospedaje), pascuaticum (renta relacionada con las tareas y las cabañas ganaderas) y el teloneum (que gravaba el tránsito de las mercancías). A los obispos diocesanos se le prohíbe intervenir en la elección de abad, derecho que les fue otorgado en el IV Concilio de Toledo (633), al tiempo que el monasterio acataba con el cumplimiento de la regla benedictina.

El carácter personal de esta relación vasallática y el interés de las dos partes por mantener vigentes los compromisos y obligaciones adquiridos en el privilegio de inmunidad, determinaron las sucesivas renovaciones de éste $(844,866$, 878 y 916). Éstas se constituyen además como la prueba más clara del compromiso de fidelidad llevado a cabo por los abades de Sant Esteve de Banyoles a los monarcas carolingios Carlos el Calvo, Luis el Tartamudo y Carlos el Simple. Este reconocimiento de la autoridad regia destaca aún más si se tiene en cuenta que las renovaciones del privilegio de inmunidad se llevaron a cabo en momentos claves de restauración del poder monárquico sobre el resto de las fuerzas magnaticias de las tierras meridionales del reino (Bernardo de Septimania, Humfrido, Bernardo de Gotia).

A mitad del siglo $\mathrm{x}$ los respectivos condes trataron de imponer su autoridad sobre las diferentes fuerzas sociales de sus correspondientes condados, apoyándose para ello en las abadías. Pero ello difícilmente se podía llevar a cabo sin dis- 
poner del apoyo del papado, nueva instancia política superior capaz de sancionar y garantizar este proyecto, el cual desde un principio estaba dificultado por el enfrentamiento de los condes con unas aristocracias locales que no estaban dispuestas a admitir los planes condales. La emergencia del papado de Roma, impulsada por el ambiente reformista pregregoriano, permitió la encomendación personal de los condes con los papas, y obtener así la garantía política y religiosa necesaria para convertirse en los nuevos patronos de los monasterios. Pero el papado a su vez también pretendía sacar partido a la nueva situación que se le ofrecía, y justificándose en la embrionaria reforma cluniacense, decide pasar a ser el nuevo señor de los monasterios del Imperio de Occidente. Esta nueva condición la ejecutarán en la concesión de bulas pontificias a las casas monásticas en las que no sólo le renuevan el viejo privilegio de inmunidad a los monasterios, sino que además se les concede la exención apostólica, que autonomizan de forma absoluta al monasterio de su obispo diocesano.

Sant Esteve de Banyoles recibe la exención apostólica por el papa Benedicto VIII en el año 1017, cuando su abad Bonfill acudió a Roma acompañando al conde de Besalú Bernat Tallaferro y al abad Oliba para instaurar el obispado de Besalú. Las disposiciones que aparecen son las típicas en las que se manifiesta el papado a la hora de señalar su tutela sobre los monasterios: elección interna y libre de los abades según dictamina la Regla de San Benito; ordenación de clérigos y consagración de abades por el obispo ordinario libremente escogido por la comunidad; prohibición al prelado local de ejercer la facultad de excomunión y de interdicto; liberación de asistencia al sínodo diocesano; participación de penitentes excluidos de culto en actividades litúrgicas mientras estuvieran en el recinto monacal; veto a cualquier irrupción forzada episcopal o civil en los cenobios o en sus pertenencias. La dependencia de la casa de Banyoles con el papado se mantendrá durante las siguientes centurias. En 1078 el conde Bernat ii de Besalú, tras expulsar al abad simoniaco de la abadía, la enfeuda a la sede romana con un censo anual de cinco sólidos ${ }^{76}$. En 1097 recibe el monasterio una nueva bula del papa Urbano $\mathrm{II}^{77}$ y será ya en 1175 cuando en un nuevo privilegio pontificio el papa Alejandro III renueve por escrito la condición de dependiente del monasterio.

Privilegios y confirmaciones pontificias permitieron al abad de Banyoles hacerse con cierto poder local y que pensamos perduró hasta el final del Antiguo Régimen. De hecho en el siglo pasado pudo Jaime de Villanueva presenciar que «el abad de este monasterio es señor jurisdiccional de la villa y de otras del entorno, cuyos bailes acuden a recibirle en su primera entrada, tirando los de Bañolas con cordones de seda la mula en que cabalga dicho señor y acompañándole los demás, precedidos de varias danzas y otras alegres comparsas» ${ }^{78}$.

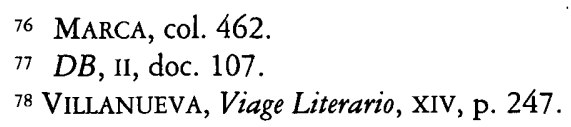

